\title{
Behaviour of hybrid timber beam-to-tubular steel column moment connections
}

\author{
V. Karagiannis, C. Málaga-Chuquitaype ${ }^{1}$ and A.Y. Elghazouli \\ Department of Civil and Environmental Engineering, Imperial College London, UK
}

\begin{abstract}
This paper presents an experimental and numerical study into the response of bolted
\end{abstract} connections between Glulam timber beams and tubular steel columns. Six specimens involving two different connection types subjected to monotonically increasing bending action are examined. The first connection type incorporates top and seat angles blind-bolted to the column and jointed to the beam through long bolts. The second connection type is formed by a steel T-stub slotted into the timber beam and connected to it by means of transverse bolts. In addition, two reinforcing techniques aimed at enhancing the response of the slotted-in T-stub configuration are investigated. These include the provision of a bottom wedge angle between the beam and the column as well as the use of perpendicular-to-grain screws to delay wood splitting. The experimental set-up, connection configurations and material properties are introduced followed by a detailed account of the test results and observations. The main behavioural patterns are identified from the experiments and key response characteristics such as stiffness, capacity and failure mechanism are discussed. This paper shows that the use of bottom wedge angles leads to significant enhancement in the flexural yield strength of the T-stub connections, accompanied by a relatively small change in the location of the bolt-group point of rotation (monitored herein by means of Digital Image Correlation techniques). Besides, the use of reinforcing screws is shown to be an effective detail for substantially increasing the rotational ductility of the connections. Finite element simulations of the tests are also presented, together with a detailed description of the modelling approaches employed, in order to gain further insight into the behaviour of the connections. Finally, the applicability of simplified component-based expressions, which are suitable for practical design assessment procedures, for the estimation of the stiffness and capacity of the proposed hybrid glulam-to-tubular column connections are presented and discussed.

Keywords: Hybrid systems, timber-steel joints, bolted connections, component models, timber reinforcement, bolt-group point of rotation

\footnotetext{
${ }^{1}$ Corresponding author; Email: c.malaga@imperial.ac.uk
} 


\section{Nomenclature}

$2 \quad A_{t}:$ Tensile stress area

$3 \quad D$ : Summation of all fasteners radii $r_{i}$ squared

4 d: Fastener diameter

$5 \quad d_{S B}:$ Standard bolt diameter

$6 \quad d_{w}$ : Bearing capacity of the steel plate inserted into the glulam beam

$7 \quad d_{s}:$ Screw diameter

$8 \quad E_{i, E m b}$ : Embedment Young's modulus

$9 \quad F_{t, R d}:$ Tension resistance of the bolts

$10 \quad F_{a x . R k}:$ Characteristic withdrawal capacity of the bolt

$11 F_{v, R k, \text { conf } 1}$ : Characteristic load-carrying capacity of a steel-to-timber connection

$12 F_{v, \text { conf } 1}$ : Effective design load-carrying capacity

$13 \quad F_{\text {shear }}$ : Shear capacity of Type 1 connection

$14 F_{T, R d}$ : Design resistance of the blind-bolted angle

$15 F_{m, d, \max }$ : Force acting at Bolt-1

$16 F_{m, d, \max , h}:$ Horizontal component of the force acting on Bolt-1

$17 F_{m, d, \max , h . k}:$ Characteristic horizontal component of the force acting on Bolt-1

$18 F_{d, H, \text { row } 1}$ : Total effective horizontal force acting on Bolt Row-1

$19 \quad F_{\text {Shear_limit }}$ : Plug shear failure capacity

$20 F_{\text {screwi }}$ : Screw force

$21 G$ : Shear modulus

$22 h_{g l}:$ Height of the glulam beam

$23 h_{e f}:$ Effective height

$24 h_{A}$ : Length of the vertical (column) leg of the angle

$25 K_{C F}$ : Bearing stiffness of the column face

$26 K_{H B}$ : Hollo-bolt axial stiffness

$27 K_{t}$ : Tension stiffness of the angle's horizontal leg

$28 K_{\text {ser }}$ : Slip modulus of each individual fastener

$29 l_{\text {ef } 1}$ : Connection effective length

$30 l_{e f}$ : Connection effective depth

$31 \quad M_{y \cdot R k}:$ Characteristic yield moment of the bolt

$32 M_{y, \text { angle }}:$ Yield moment capacity of Type 1 connection

$33 M_{\text {shear }}$ : Moment capacity at ultimate associated with brittle shear failure

$34 \quad M_{d}:$ Applied moment

$35 M_{d, y}:$ Moment capacity of Type 2 connection

$36 \quad M_{d, P S}$ : Moment capacity for plug shear failure

$37 \quad M_{y, s}:$ Yield moment of the screw 
$1 \quad M_{T}$ : Total moment capacity

$2 M_{d, \text { angle }}$ : Moment capacity associated with the wedge angle contribution in Type 2

3 connection

$4 \quad n_{b, e f}$ : Effective number of fasteners connecting the angle to the glulam beam in the direction

5 parallel to the grain

$6 n_{b}$ : Number of bolts in the direction parallel to the width of the beam

$7 \quad n_{s, p l}:$ Number of bolt-rows.

$8 n_{\text {row } 1}$ : Number of bolts in the direction parallel to the grain

$9 n_{\text {row } 1, e f}$ : Effective number of bolts in the direction parallel to the grain

$10 P$ : Ratio between the radius of the foundation zone and the fastener diameter

$11 R_{i}$ : Strength associated with screw failure

$12 r_{\text {fill }}$ : Corner radius of the angle

$13 r_{\text {max }}$ : Position vector of Bolt-1 with respect to the point of rotation

$14 r_{i}$ : Distance from fastener to the point of rotation for Type 2 connection

$15 S_{\text {config1,init }}$ : Rotation stiffness of Type 1 connection

$16 S_{\text {config } 2}$ : Rotation stiffness of Type 2 connection

$17 t_{f}$ : Angle thickness

$18 t_{1}$ : Distance parallel to the width of the beam between the side of the beam and the inserted 19 metal plate

$20 t_{\text {Tstub }}$ : Thickness of the metallic plate

$21 w_{f}$ : Width of the angle

$22 w_{b}$ : Width of the glulam beam

$23 \quad y_{1}$ : Vertical distance between Bolt-1 and the centre of rotation

$24 y_{A}$ : Distance between point of rotation and the bearing zone of the wedge angle

$25 \beta_{1}, \beta_{2}, \gamma_{1}$ and $\gamma_{2}$ : Empirical parameters

$26 \gamma_{M}$ : Material safety factor

$27 \sigma_{E m b}:$ Embedment stress

$28 \sigma_{F Z}$ : Stress of the foundation zone

$29 \sigma_{11, e m b, k}:$ Characteristic embedment strength parallel to the grain

$30 \sigma_{y, f}:$ Yield stress of the angle

$31 \sigma_{u b}:$ Tensile strength the appropriate bolt grade

$32 \sigma_{c, 90}$ : Compression strength of the beam perpendicular to the direction of the grain

$33 \sigma_{v, k}:$ Characteristic shear strength of glulam

$34 \rho:$ Wood density 


\section{1. Introduction}

Hybrid structural systems that combine materials of complementary properties have the potential to achieve significant levels of efficiency. In this context, the behaviour of hybrid reinforced concrete beams-to- steel columns has been the subject of a number of studies [e.g. $1,2]$. In contrast, despite their merits, research on the response of timber-steel hybrid systems is less common. Available investigations include the study of Dickof et al. [3] which proposed to combine the lightness, economy and sustainable characteristics of laminated timber panels with the ductility of steel beam-column elements to create a multi-storey timber-steel framed structure of high lateral stiffness. Likewise, the use of hybrid timber-steel flooring systems formed of Cross-Laminated Timber (CLT) and steel beams has been studied by Okutu et al. [4]. It was shown that the use of timber flooring systems results in a significantly lighter structure leading to reduced column sizes and more economical foundations. Other examples of the implementation of timber-steel hybrid systems include the Earth Science Building of the University of British Columbia in Canada [5] and the Banyan Wharf building in the UK [6] that employ moment resisting and shear wall configurations, respectively.

Structural timber clearly offers a number of advantages, especially in terms of carbon storage potential, construction economy and lightness. In this context, the architectural versatility of framed construction, relative to solid wall systems, can be further enhanced by the aesthetic and structural efficiency of tubular columns. Such configuration has the advantage of requiring smaller column sections (in comparison with a whole timber moment resisting frame solution) and a relatively less constrained connection configuration due to the avoidance of the perpendicular-to-grain weaknesses of a wooden column. However, the lack of practical details for connecting tubular columns and timber beams may limit the application of this hybrid solution. In terms of timber connections, Bainbridge and Mettem [7] conducted a review on available connection configurations for whole timber momentresistant frames and highlighted the benefits of using mechanical dowel type connection. Similarly, significant research has been recently conducted on practical semi-rigid connection alternatives in whole steel frames with tubular columns [8-11]. Nevertheless, details for semirigid connections joining timber beams and tubular columns have not been proposed. 
1 This paper deals with the flexural response of a new type of hybrid bolted connections 2 between Glulam timber beams and tubular steel columns by means of numerical and experimental studies. Issues related to the shear resistance and multiple load combinations are outside the scope of this paper. A total of six connection specimens are tested under monotonically increasing bending action. Two connection configuration alternatives are examined. The first connection type incorporates top and seat angles blind-bolted to the column and jointed to the beam via four vertical long bolts. The second joint configuration employs a steel T-stub pre-welded to the steel column, and slotted-in and bolted to the timber beam by means of twenty transverse bolts. In addition, two reinforcing techniques aimed at enhancing the response of the slotted-in T-stub configuration are investigated. The first reinforcing method involves the use of a bottom wedge angle that enforces a permanent bearing surface in the joint thus increasing its capacity. The second reinforcing technique examined herein employs steel screws inserted in the direction perpendicular-to-grain aimed at delaying or preventing splitting of the wood fibres. The test set-up, specimen details and material characterization are first introduced followed by a detailed account of the experimental findings. Continuous measurements, obtained by means of Digital Image Correlation (DIC) techniques, are presented and employed to obtain a full account of the migration of the point of rotation within the bolt group. Detailed Finite Element models are presented and validated against the experimental results. These models make use of the foundation approach, which was initially proposed by Fochi [12] and Hong [13], and was recently modified by Karagiannis et al. [14] in order to represent faithfully the crushing behaviour of timber during embedment. It is shown that the hybrid connection configurations considered offer reasonable levels of stiffness and capacity within the range of typical semirigid connections. Subsequently, the applicability of simplified component-based formulations for estimating the stiffness and capacity of the proposed hybrid glulam-totubular column connections are assessed. Besides guiding the connection design, the proposed formulations are essential for the execution of global frame analysis for which an appropriate balance between ease and rigour should be sought.

\section{Experimental arrangement and specimen details}

\subsection{Test set-up}

Figure 1 shows the experimental set-up used for testing the glulam beam-to-steel column connections under bending. Preliminary numerical investigations [15] and previous research 
on semi-rigid connection to tubular columns [16] have shown that when the column length exceeds $1 \mathrm{~m}$, it does not have a significant influence on the connection response. Therefore, a 2-metre long steel SHS (Square Hollow Section) column was employed for all tests. The column was fixed to the strong floor at both ends by means of stressing bolts and plates as depicted in Figure 1. A double-hinged hydraulic actuator operating in displacement control was attached to the tip of the glulam beam through a specially designed clamping device. The displacement at the top of the beam was increased gradually at a rate of around $2 \mathrm{~mm} / \mathrm{min}$ until the stroke of the actuator was reached (at $200 \mathrm{~mm}$ of top displacement) or until clear connection failure was observed. In order to eliminate the possibility of out-of-plane displacement of the beam, a frictionless lateral restraint was adopted as indicated in Figure 1.

The displacement transducer and load cell incorporated within the actuator were employed to record the applied displacement and corresponding load at the tip of the beam, respectively. Besides, an inclinometer was attached to the beam to verify its angle of rotation. The fixed position of the column relative to the floor was continuously monitored by means of displacement transducers. A number of strain gauges were used in each specimen, and digital image correlation (DIC) was also employed, as discussed in subsequent sections. A S355 Steel Square Hollow Section of 150x10 mm was used for the column in all cases while GL28h glulam beams with laminas of $45 \mathrm{~mm}$ were utilised. Two timber beam sections (280x140 mm and 405x140) were used depending on the connection type as described below.

\subsection{Connection Specimens}

As noted before, two connection types were examined. The first (referred to as Type 1) incorporates top and seat angle brackets blind-bolted to the SHS column and tied to the glulam beam by means of long steel bolts running parallel to the beam depth. The second detail (referred to as Type 2) uses a steel T-stub, with its flanges welded to the SHS section, while its web is slotted into the timber beam. Twenty transverse bolts are used to attach the stub to the timber beam as depicted in Figure 2. Further specimen details are given below.

\subsubsection{Top and seat bolted angle connections (Type 1)}

For Type 1 (top and seat angle) connections, L 200x150 mm angles made of S275 steel were blind-bolted to the SHS column by means of M16 Grade 10.9 Lindapter Hollo-bolts [17]. The horizontal (beam) legs of the top and seat angles were connected with each other and with the 
timber beam via four long bolts (12 mm diameter and Grade 10.9) passing through the beam depth as depicted in Figure 2. Tightening torques of $190 \mathrm{Nm}$ and $100 \mathrm{Nm}$ were applied to the Hollo-bolts and to the long bolts, respectively. Given the availability of previous experimental data on the response of SHS faces in tension, compression and bending [11, 18], as well as previous experimental research on the behaviour of blind-bolt/angle assemblages $[9,16,19]$, focus was mainly given to the interaction between timber and steel components in this study. This was achieved by employing relatively stiff angles with different thicknesses $(15 \mathrm{~mm}$ and $12 \mathrm{~mm})$ selected in order to avoid angle failure whilst allowing for different degrees of timber-steel interaction. Table 1, and Figures 2(a) and 3, provide the details of the two tests conducted on Type 1 connection specimens (Specimens $\mathrm{S} 1$ and S2). It should be noted that the dimensions $a^{\prime}-g^{\prime}$, as shown in Figure 3, were selected in accordance with Eurocode 3 [20] with the purpose of avoiding premature steel failure. Similarly, the minimum allowable bolt-to-bolt distances for timber and steel given in Table 8.4 of Eurocode 5 [21] and Table 3.3 of Eurocode 3 [20] were respected.

\subsubsection{Slotted-in T-stub connections with bolts (Type 2)}

The configuration adopted for Type 2 connections is depicted in Figure 2(b). This connection employs a steel T-stub pre-welded to the SHS column and slotted vertically into the glulam beam as shown in Figure 4. In addition, twenty M10 threated rods of Grade 10.9 are installed perpendicularly to the steel plate through the full width of the glulam beam and tightened with nuts. The washers employed had an outer and inner diameters of 20 and $10 \mathrm{~mm}$, respectively, and a thickness of $2 \mathrm{~mm}$. A total of four tests were performed on this type of connection. Details of the tested specimens are given in Table 2 and Figure 4. Specimen S3 represents the original configuration of Type 2 connection as described above. In addition, a number of reinforcing techniques were examined in Specimens S4, S5 and S6 aimed at enhancing the strength and ductility of the connection. Specimens S4 and S6 incorporated a bottom angle wedged between the timber beam and the SHS column, which has the effect of providing a continuous bearing support and of moving the point of rotation of the joint from its theoretical point $\mathrm{C}$ towards the bottom as will be discussed in Section 3.2.3. Also, with the purpose of improving the overall joint ductility by preventing premature splitting failure of the wood, 32 carbon-steel screws were inserted in Specimens S5 and S6 near the bolts, in the areas where high stresses were expected as shown in Figure 5. These screws were $120 \mathrm{~mm}$ long and had a diameter of $6 \mathrm{~mm}$. 


\subsection{Material characterization}

A detailed experimental assessment was conducted in order to characterize the material properties of the structural timber components employed [15]. This included: full-scale 4point bending tests, compression tests in both parallel and perpendicular to the grain directions as well as tension tests. All the tests were performed in accordance with the European Standard EN 384:2010 [22] and their corresponding results are summarized in Table 3 in terms of mean values and their associated coefficients of variation obtained from at least 8 samples in each case. In addition, fourteen coupon tests were conducted to obtain the mean yield and mean ultimate strength values of the steel components as presented in Table 4. The same batch of Hollo-bolts adopted by Elghazouli et al. [9] was used, for which the axial capacity was determined experimentally as $78 \mathrm{kN}$.

\section{Test results and observations}

\subsection{Top and seat bolted angle connections (Type 1)}

Table 5 summarises the main response parameters obtained from the tests on steel-timber connections of Type 1 (Top and seat bolted angle connections). The initial stiffness and the yield moment were obtained from a bilinear idealisation of the experimentally-obtained moment-rotation curves. Figures 6 to 10 show the key experimental results in terms of deformation patterns, strain measurements, and moment-rotation relationships.

As explained before, the experimental programme was designed in order to induce different levels of interaction between the steel components and the timber beam. To this end, the effects of decreasing the angle thickness from $15 \mathrm{~mm}$ in Specimen $\mathrm{S} 1$ to $12 \mathrm{~mm}$ in Specimen S2 can be observed by directly comparing the results of both specimens in Table 5 and Figures 6 to 8 . It can be concluded that for the relatively stiff angles employed, a $3 \mathrm{~mm}$ reduction in angle thickness has negligible influence on the initial rotational stiffness of the connection. However, this angle thickness decrease is sufficient to cause notable differences in the connection yield strength and ultimate capacity. The flexural yield and ultimate strength of Specimen S1 (with $15 \mathrm{~mm}$ angles) were approximately $34 \%$ and $15 \%$ higher than that of S2 (with $12 \mathrm{~mm}$ angles), respectively. This difference in ultimate connection strength results from the dissimilar failure modes observed in Figure 6a (Specimen S1) and 6b (Specimen S2). From these figures it can be seen that larger plastic deformations are 
accumulated in the thinner angle (Specimen S2) whereas the thicker angles of Specimen S1 are able to transfer larger forces into the long bolts, eventually leading to a bolt-row shear failure in the timber at a maximum rotation of $90 \mathrm{mrad}$. It should be noted that the test on Specimen S2 was halted at the maximum stroke of the actuator corresponding to a joint rotation of $100 \mathrm{mrad}$ associated with a peak flexural strength of $42.5 \mathrm{kNm}$. These differences between the two deformation modes can be further explained with the aid of Figures $8 \mathrm{~b}$ and $8 \mathrm{c}$ that present the corresponding strain measurements. In the case of Specimen S2, yielding in the top angle occurred first near the toe of the vertical (column) leg (MS2 location in Figure 8c) followed by the development of large plastic deformations. Plastic strain levels were also attained in the vertical (column) leg between the Hollo-bolts for rotations greater than $28 \mathrm{mrad}$ (MS1 location in Figure 8a). Conversely, and unlike Specimen S2, limited plastic deformation was generated in the vertical leg of the top angle between the Hollo-bolts in Specimen S1 (MS1 location in Figure 8a). This resulted in lower plastic strains around the fillet area (locations MS2 and MS3 in Figure 8a) and a stiffer response of the angle leading to greater forces on the long bolts attached to the glulam beam. Finally, very limited plastic deformations were observed in the bottom angles of both connection specimens.

\subsection{Slotted-in T-stub connections with bolts (Type 2)}

Table 6 summarises the main response parameters for connection Type 2 while Figures 9 and 10 show the key experimental results in terms of deformation patterns and moment-rotation relationships. The initial rotational stiffness and yield moments presented in Table 6 were obtained from a bilinear idealisation of the corresponding moment-rotation curves.

\subsubsection{Deformation patterns and failure modes}

Figure 9 shows the failure modes of the four Type 2 specimens tested in the present study. It can be observed from Figure 9a that Specimen S3 developed shear failures at the transverse section planes containing the top and bottom outmost bolt-rows. The top shear crack, which propagates inside the timber beam, is wider than the crack at the bottom row due to the configuration of stresses in the connection with the tension stresses developed in the upper part of the beam contributing towards the crack opening. In contrast, when reinforcing screws were inserted in the critically stressed zones, as in Specimen S5 of Figure 9c, shear splitting was effectively prevented. Alternatively, when a bottom wedge angle was utilised in Specimen S4 without reinforcing screws (Figure 9b), the failure mechanism involved a 
combination of compressive failure and wood splitting at the bottom of the glulam beam. This failure mechanism is caused by the compression forces resulting from the continuous bearing of the beam onto the angle wedge. This compression crushing was observed even in the case of Specimen S6, which besides the wedge angle also incorporated screw reinforcement as shown in Figure 9d. It is also worth noting that Specimens S5 and S6 did not reach failure and achieved maximum moments of 38.9 and $54.4 \mathrm{kN} / \mathrm{m}$, respectively, when the actuator attained its full stroke (at $130 \mathrm{mrad}$ of rotation). The different failure modes developed in these connections have significant effects on the moment-rotation curves as discussed below with particular reference to the contribution of wedge angles and screw reinforcement.

\subsubsection{Influence of screw reinforcement}

The effects of the presence of screws on the response of the connection can be explored by comparing the experimental results of Specimen S3 with that of Specimen S5 (both without wedge angle) as well as the responses of Specimens S4 and S6 (both with wedge angle). As indicated in Figure 10 and Table 6, the ultimate capacity of Specimen S5 was around 34\% higher than that of S3, whereas the capacity of Specimen S6 was around 24\% higher than that of S4. This significant difference in ultimate capacity is a consequence of the improved ductility experienced by connections with screw reinforcement. These enhancements are brought about by the action of screws in delaying the splitting of wood along their axis while at the same time resisting transverse forces perpendicular to their longitudinal axis by bending. Importantly, the yield capacity of the connection appears to be insensitive to the presence of the screws since their favourable effects become significant only after some plastic deformation has already taken place at rotations of $\sim 50 \mathrm{mrad}$ or greater.

\subsubsection{Influence of wedge-angle}

The influence of the provision of a bottom wedge angle on the connection moment-rotation response can be examined by comparing the results of Specimens S3 (without wedge angle) and S4 (with wedge angle). As Figure 10 suggests, the use of a contact angle to enforce early and continuous bearing contact between the bottom part of the beam and the column significantly enhances the stiffness and capacity of the connection. As a general remark, all four Type 2 specimens have an almost identical initial stiffness. However, between $\sim 1$ and 2 mrad of joint rotation, specimens without wedge angles (i.e. S3 and S5) experience a more pronounced bolt slippage. Importantly, this slippage phenomenon is mitigated in S4 and S6 
due to the continuous bearing support provided by the bottom wedge angle. Additionally, it can be noted from Figure 10 and Table 6, that the capacity of Specimen S4 was around 53\% higher than that of S3 for which the only difference was the use of a bottom wedge angle in Specimen S4. This gain in capacity is caused by a reconfiguration of stresses instigated by the introduction of a compressive bearing zone at the bottom of the beam as well as the modification of the point of rotation in the joint that lengthened the lever arm as described in the following section.

\subsubsection{Non-contact field strain (DIC) measurements of point of rotation}

The exact location of the point of rotation was examined with the aid of a LaVision [23] Digital Image Correlation (DIC) system. Two cameras spaced at $500 \mathrm{~mm}$ from each other and rotated $15^{\circ}$ inwards, were placed at a distance of $1500 \mathrm{~mm}$ from the specimen. The area of interest was prepared by spraying a randomized pattern of black dots onto a white prepainted beam surface. High quality pictures of 5 mega pixels were taken at a rate of 6 frames per minute during testing. The DIC algorithm employed [23] tracks the motion of surface patterns and calculates the corresponding 3D strain fields at each frame.

Figures $11 \mathrm{a}$ and $11 \mathrm{~b}$ show the displacement contours in the $y$ (along the beam axis) and $z$ (perpendicular to the beam axis) directions for Specimens S5 and S6 respectively, at a joint rotation of $9 \mathrm{mrad}$. From the information given in these figures, the neutral planes parallel to the $y$ and $z$ directions can be easily identified. The point of rotation is located at the intersection between those two planes of zero relative displacement. It is important to note that Specimens S3 and S4 presented an identical evolution in the location of their points of rotation as those observed in Specimens S5 and S6, respectively.

By following the procedure described above, an accurate and continuous monitoring of the point of rotation within the bolt group of Type 2 connections can be made. Figure 12 depicts the evolution of the point of rotation (indicated as a red dot) at different levels of joint rotation for specimens S5 and S6. It is observed from Figure 12 that after a certain level of rotation is attained (i.e. $34 \mathrm{mrad}$ in S5 and $25 \mathrm{mrad}$ in S6) the location of the point of rotation remains unaltered until the end of the test. It is also interesting to note with reference to Figures 10 and 12 that for rotations larger than $8.82 \mathrm{mrad}$ the point of rotation displaces vertically with negligible horizontal translation in both specimens, whereas prior to $8.82 \mathrm{mrad}$ of joint rotation, the main translation component in the point of rotation's motion is 
horizontal. This level of connection rotation $(8.82 \mathrm{mrad})$ corresponds to the point at which Bolt-1 (Figure 12) starts yielding.

Finally, Figure 12 also depicts the ideal locations for the points of rotation (shown as a purple dot) at the centroids of the fastener groups obtained with a rigid motion assumption. In the case of Specimen S5 without the bottom wedge angle (Figure 12a) the centre of rotation lies at the geometric centre of the group. On the other hand, in order to offer a practical estimation of the location of the point of rotation in the presence of a wedge angle (as in Specimen S6 in Figure 12b), the vertical leg of the angle was idealized as a continuous series of equivalent bolts of equal diameter $(\mathrm{d}=10 \mathrm{~mm})$. It can be appreciated that although some minor discrepancies are present between the ideal estimations and the real location, the magnitude and effects of alternation of the bolt group configuration are well represented, and the predicted points of rotation can be employed for the calculation of the connection stiffness and strength as described in the following sections.

\section{Numerical Assessments}

The experimental results and observations presented in the previous section provide essential information for the validation of numerical and analytical models of the hybrid timber beamto-steel column connections proposed herein. Therefore, this section describes detailed continuum numerical models developed using the general purpose finite element (FE) program ABAQUS [24] with the aim of simulating the response of top and seat bolted details as well as T-stub slotted-in configurations. A detailed discussion of the modelling approach is presented below followed by a description of the modelling parameters and validation studies. The models proposed below make use of an advanced numerical strategy for simulating the nonlinear wood response of embedding fasteners (referred to as the modified foundation approach). These models constitute the first step towards providing a tool that can be used for the future extension of the experimental dataset.

\subsection{Modified foundation embedment modelling applied to groups of fasteners}

Previous research $[14,25]$ has demonstrated that the response of dowelled/bolted connections in timber is a complex multi-dimensional problem for which accurate modelling is not possible by means of conventional FE strategies that assume standard material constitutive properties. Hence, the foundation zone approach [12-14] is utilised herein to incorporate the 
1 effects of localised wood crushing. The method hinges around the definition of a zone of modified material properties within a certain volume around the bolt holes. This volume is referred to as the foundation zone (presented in white in Figure 13 for Specimen S3 for illustrative purposes) for which the material properties are determined via pre-defined calibration procedures. In general, the foundation model assumes a cylindrical volume with dimensions proportional to the diameter of the fastener, and this is the approach adopted when modelling Type 1 Connections. However, in the case of Type 2 Connections, involving a group of various fasteners, it is more convenient to merge their corresponding foundation zones into a larger enclosing volume defined by the radius $\mathrm{R}_{\mathrm{FZ}}$ associated with each individual dowel, as shown in Figure 13.

\subsection{Equivalent material properties for the foundation zone}

The mean material properties from the tests described in the previous section were adopted for the main wood volume outside the foundation zone [14]. On the other hand, as discussed before, relatively softer and weaker material parameters were specified for the foundation volume. For Type 1 Connections, the material properties for the foundation zone were directly based on the work of Karagiannis et al. [14] which utilized $12 \mathrm{~mm}$ fasteners embedding on glulam. However, since the $10 \mathrm{~mm}$ bolts employed in Type 2 Connections were not directly considered in previous studies [14], a linear extrapolation process was carried out to determine the required material modelling parameters. Table 7 presents the material parameters as obtained from the embedment tests (identified by the subscript $E m b$ ) with fasteners of diameters 12 and $16 \mathrm{~mm}$ together with those estimated for $10 \mathrm{~mm}$ bolts. In this table, the indices 1 to 3 refer to the three principal stress directions.

The foundation moduli, $E_{i, E m b}$, (for $i=1,2,3$ ), were estimated in accordance with the findings of Hong [13] which showed that the influence of the fastener diameter on the embedment stiffness is greater for large diameters $(\mathrm{d}>12 \mathrm{~mm})$, and becomes negligible for smaller diameters $(\mathrm{d} \leq 12 \mathrm{~mm})$. Furthermore, these size effects are more evident in cases where the direction of the grain is parallel to the direction of the load. Hence, as shown in Table 7, the estimated values for the foundation moduli, $E_{i, E m b}$, with $\mathrm{d}=10 \mathrm{~mm}$ were assumed to be identical to those obtained for $\mathrm{d}=12 \mathrm{~mm}$. Similarly, the embedment principal stress $\sigma_{i i}(i=1,2,3)$ for fastener with $\mathrm{d}=10 \mathrm{~mm}$ was also estimated through linear extrapolation. In the case of Poisson ratios and shear strengths, nominal values were assumed 
regardless of the foundation zone distinction [14]. Similarly, the values for the shear modulus $G$ within the foundation zone were estimated from the empirical formula given in EN $338: 2009[26]$ as:

$$
G_{12}=\frac{E_{11}}{16}
$$

The following expressions, proposed by Karagiannis et. al. [14], were used for the determination of effective Elastic Modulus and yield stresses within the foundation zone in the directions parallel $\left(E_{1, F Z} \& \sigma_{11, F Z}\right)$, and perpendicular $\left(E_{2, F Z} \& \sigma_{22, F Z}\right)$, to the grain orientation:

$$
\begin{aligned}
E_{1, F Z} & =\left(1+\beta_{1} \frac{P}{t}\right) E_{1, E m b} \\
E_{2, F Z} & =\left(1+\beta_{2} \frac{P}{t}\right) E_{2, E m b} \\
\sigma_{11, F Z} & =\left(1-\gamma_{1} \frac{P}{d \cdot t}\right) \sigma_{11, E m b} \\
\sigma_{22, F Z} & =\left(1-\gamma_{2} \frac{P}{d \cdot t}\right) \sigma_{22, E m b}
\end{aligned}
$$

where, $t$ is the width of the glulam beam in $\mathrm{mm}, d$ is the diameter of the bolts in $\mathrm{mm}, E_{E m b}$ is the embedment Young's modulus in MPa, $E_{F Z}$ is Young's modulus of the foundation zone in $\mathrm{MPa}, \sigma_{E m b}$ is the embedment stress in $\mathrm{MPa}$, and $\sigma_{F Z}$ is the stress of the foundation zone in MPa; $\beta_{1}, \beta_{2}, \gamma_{1}$ and $\gamma_{2}$ are empirical parameters, as discussed in previous studies [14], whose values are presented in Tables 8 and 9 (noting that values for $\mathrm{d}=10 \mathrm{~mm}$ were linearly extrapolated from available values for 12 and $16 \mathrm{~mm}$ [14]).

\subsection{Connection modelling details}

Detailed 3D models were constructed using the FE program ABAQUS V6.14 [24]. Typical models for both connection configurations are illustrated in Figure 14. The models made use of 8-node brick solid elements of Type C3D8 for all steel and timber components except for the reinforcing screws. The screws in Specimens S5 and S6 were simulated with 3D 2-node linear beam elements of Type B31. Symmetry conditions were used in order to save computational resources as indicated in Figure 14. A tri-linear kinematic hardening representation with an elastic modulus of $210 \mathrm{GPa}$ and a Poisson's ratio of 0.3 was employed for the steel components while an orthotropic Hill's plasticity model with isotropic hardening 
was employed for the wood components. This steel stress-strain relationship incorporates an elastic stage, a constant stress plateau up to a strain level of approximately 0.01 , and a $1 \%$ strain-hardening stiffness thereafter. Similarly, the experimentally-obtained mean material properties of wood were adopted for the beam outside the foundation zone while modified values of strength and stiffness were employed within the foundation zone as described in the previous section.

Contact phenomena between steel and wood were modelled by defining pairs of "master" and "slave" contact surfaces in ABAQUS. To this end, the relatively more flexible wood surface was defined as "slave" whereas the stiffer steel surface was chosen as "master". The hard contact over-closure pressure relationship of ABAQUS was modified by adopting a linear relationship with significantly stiff response to minimise non-convergence. A friction coefficient of $\mu=0.7$ was used as proposed by the experimental study of Smith [27].

A number of mesh size sensitivity studies were carried out in order to arrive at an optimum element size distribution. The adopted mesh arrangement involved a coarser mesh within the main body of the wood sample, whereas a finer mesh was employed for the foundation zone around the bolt-hole. The dimensions of the finally adopted mesh ranged between 1 and 5 $\mathrm{mm}$.

\subsection{Model validations}

The finite element (FE) models described above were validated against the results from the experimental programme described in Section 2. Figure 15 presents the comparisons between the numerical simulations and the experimental curves for Specimens S1 and S2. This figure demonstrates that reasonable estimates of stiffness and capacity can be obtained by means of the detailed FE model described above. Some differences are evident between the FE predictions and the observed moment-rotation relationships starting at approximately 1.5 mrad of rotation and at around $6 \mathrm{kNm}$ of moment capacity. This phenomenon can be attributed to bolt slippage that occurs through a series of instantaneous movements in the numerical model whereas a more gradual slip displacement was observed in the tests. After slippage, contact between the steel fasteners and the timber members is resumed leading to an instantaneous stiffness increment before plastic stress levels are recovered in the wood. Nevertheless, a good agreement can be observed between the numerical estimation and the experimental moment capacity with a maximum difference of less than $\pm 10 \%$ for both 
specimens. The numerical FE analysis of Specimen S1 stopped at $\sim 40 \mathrm{mrad}$ due to the large concentration of element deformations around the bolt area which correlates well with the experimentally observed shear failure in this specimen.

Figure 16 illustrates the deformation patterns of the top angle of Specimens S1 and S2 at 40 mrads and 80 mrads rotation, respectively, together with the corresponding numerical predictions. From this figure it is evident that the deformation and plastic mechanisms are well captured by the proposed FE model. Similarly, the higher concentration of non-linear strains at the blind-bolt row-line observed in Specimen S2, in comparison with Specimen S1, is also captured by the numerical simulations.

Figure 17 presents a comparison between experimental and numerical moment-rotation responses of Type 2 Specimens S3, S4, S5 and S6. The plots confirm that the numerical predictions are in good agreement with the experimental results. Importantly, the numerical models were able to capture the full non-linear response of Specimens S5 and S6 very accurately, including their ultimate capacity. In the case of Specimens S3 and S4, the response of the connection was very well predicted up to around $60 \mathrm{mrad}$ of joint rotation. Larger rotations are associated with the initiation of shear failure in the glulam beam (see Figures $9 \mathrm{a}$ and $9 \mathrm{~b}$ ) and the corresponding onset of significant damage interactions, which are not taken into account within the constitutive material models employed. Also, all FE models experienced an instantaneous bolt slippage at around $1.5 \mathrm{kNm}$ of moment due to the clearance between the bolt shank and the glulam beam leading to instantaneous loss of stiffness and the subsequent steep response once contact is regained. The effects of the wedge at the bottom in mitigating the amount of slippage are also evident when the numerical moment rotation relationships of Specimens S4 and S3 as well as S6 and S5 are compared.

In addition to the experimental and numerical comparisons already discussed, Figure 15a and 17a presents the moment-rotation relationship obtained from a conventional FE modelling approach without the definition of a foundation zone for illustration purposes. It is evident from these figures that the implementation of the foundation zone is essential for obtaining accurate predictions of the response of timber connections since the absence of damage related to localised wood crushing during embedment can lead to significant over-predictions of the joint response. 
1 Figure 18 compares the residual plastic deformation of the outermost bolt in the tensile region 2 of Specimen S3 (see Figure 9a) with the corresponding numerical simulation. It can be observed from Figure 18 that the model is able to capture the deformation pattern of the bolt including the full development of a plastic hinge and the residual deformation for a peak moment of $28.6 \mathrm{kN}$. A further comparison can be established in the case of the screws used to reinforce Type 2 connections (Specimen S6) presented in Figure 19. This figure illustrates the close comparison of residual deformed states, including the location and number of plastic hinges in the most stressed screw of Specimen S6. All these results and comparisons provide confidence in the modelling strategy and validate the accuracy of the proposed models for future studies that can complement the experimental findings described herein.

\section{Component-based models}

In this section, the widely used simplified component approach [20,21,28], which is suitable for practical design and assessment applications, is utilised for establishing the stiffness and capacity of hybrid timber beam-to-steel column connections. The evaluation of the flexural capacity of hybrid connections is discussed first with reference to Type 1 and Type 2 configurations, and considering shear failure modes where relevant. Subsequently, the prediction of the connection stiffness is considered. Finally, the results of the expressions presented are validated against the experimental results presented in earlier sections.

\subsection{Capacity estimation of Type 1 connections}

The strength of this type of connection (i.e. top and seat angle with bolts) is governed by two main failure modes. The first mode is associated with the bending resistance of the blindbolted angles while the second mode is related to the interaction between the glulam beam and the fastener-angle assemblage. In addition, prediction of the row shear fracture capacity can be important for the estimation of the ultimate resistance of the connection as observed from the results of Specimen S1 presented above.

\subsubsection{Blind-bolted Angle Capacity}

According to EC3 Part 1-8 Section 6.2.6.6 [20], the tension design resistance and the failure mode of a bolted angle in bending can be associated with those of an equivalent T-stub 
1 flange. Therefore, the design resistance of the blind-bolted angle $\left(F_{T, R d}\right)$ can be estimated as the smallest of the failure modes represented in Equations 6 to 8 [20] as follows:

$$
F_{T, R d}=\min \left\{\begin{array}{l}
\frac{4 \cdot M_{p l, 1, R d}}{f^{\prime}-t_{f}-r_{f i l l}} \\
\frac{2 \cdot M_{p l, 2, R d}+g^{\prime} \cdot \sum F_{t, R d}}{\left(f^{\prime}-t_{f}-r_{f i l l}\right)+g^{\prime}} \\
\sum F_{t, R d}
\end{array}\right.
$$

with:

$$
M_{p l, 1, R d}=M_{p l, 2, R d}=\frac{w_{f}}{2} \frac{t_{f}^{2} \cdot \sigma_{y, f}}{4}
$$

where, $w_{f}$ is the angle width, $t_{f}$ is the angle thickness, $r_{f i l l}$ is the corner radius of the angle, $f^{\prime}$ and $g^{\prime}$ are the gauge distances defined in Figure 3 which can be modified to account for the inherent rotational flexibility of the Hollo-bolt as suggested in previous studies $[16,19]$, and $\sum F_{t, R d}$ is the total value of the tension resistance $F_{t, R d}$ for all the fasteners in the angle.

\subsubsection{Vertical bolts capacity}

The capacity associated with the long bolt-timber interaction can be determined from the expressions given in Chapter 8.2.3 of Eurocode 5 [21] for timber-to-steel dowel-type joints. The failure modes experienced by these connections depend on the thickness of the steel angle $\left(t_{f}\right)$, the diameter of the standard bolts $\left(d_{S B}\right)$, the characteristic embedment strength parallel to the grain $\left(\sigma_{11, e m b, k}\right)$, the distance parallel to the width of the beam between the side of the beam and the inserted metal plate $\left(t_{1}\right)$, the characteristic sectional yield moment of the bolt $\left(\mathrm{M}_{\mathrm{y} \cdot \mathrm{Rk}}\right)$ and the characteristic withdrawal capacity of the bolt in $\mathrm{kN}\left(\mathrm{F}_{\mathrm{ax} \cdot \mathrm{Rk}}\right)$. Therefore, by considering the upper tensioned part of the joint as a single shear spring component rotating with respect to the bottom fibre of the beam, the bending capacity of Specimens S1 and S2 can be obtained. To this end, the characteristic load-carrying capacity $\left(\mathrm{F}_{\mathrm{V}, \mathrm{Rk}, \mathrm{conf} 1}\right)$ of the tensioned component of the connection can be estimated from the following expressions which which satisfy the relationship $t_{f} \geq d_{S B}$ (thick steel plate): 


$$
F_{v, R k, \text { conf } 1}=\min \left\{\begin{array}{l}
\sigma_{11, e m b, k} \cdot h_{g l} \cdot d_{S B} \\
\sigma_{11, e m b, k} \cdot h_{g l} \cdot d_{S B}\left[\sqrt{2+\frac{4 M_{y, R k}}{\sigma_{11, e m b, k} \cdot h_{g l}^{2} \cdot d_{S B}}}-1\right]+\frac{F_{a x, R k}}{4} \\
2.3 \sqrt{M_{y, R k} \cdot \sigma_{11, e m b, k} \cdot d_{S B}}+\frac{F_{a x, R k}}{4}
\end{array}\right.
$$

Likewise, the withdrawal capacity of the bolt can be estimated from the following relationship [21]:

$$
F_{a x . R k}=\min \left\{\begin{array}{l}
\sigma_{u b} \cdot A_{t} \\
3 \cdot \sigma_{c, 90} \cdot \frac{\pi}{4}\left[d_{w}-\left(d_{S B}+1\right)\right]
\end{array}\right.
$$

where $\sigma_{u b}$ is the tensile strength the appropriate bolt grade in $\mathrm{MPa}, A_{t}$ is the tensile stress area in $\mathrm{mm}^{2}, \sigma_{c, 90}$ is the compression strength of the glulam beam perpendicular to the direction of the grain in $\mathrm{MPa}$, and $d_{w}$ is the bearing capacity of the steel plate inserted into the glulam beam in $\mathrm{mm}$ and can be taken as:

$$
d_{w}=\min \left\{\begin{array}{l}
12 \cdot t_{f} \\
4 \cdot d_{S B}
\end{array}\right.
$$

Also, as suggested in [21], an upper bound of $25 \%$ of the Johansen yield equation was considered for the rope effect which represents the additional in plane contribution brought about by tensile forces developed in highly deformed fasteners. Finally, by including all fasteners parallel to the direction of the grain, the effective design load-carrying capacity $F_{v, \text { conf } 1}$ can be determined as:

$$
F_{v, \text { conf } 1}=\frac{1}{\gamma_{M}} n_{b, e f} \cdot m_{b} \cdot F_{v, R k, c o n f 1}
$$

with,

$$
n_{b, e f}=\min \left\{\begin{array}{c}
n_{b} \\
n_{b}^{0.9} \sqrt[4]{\frac{d^{\prime}}{13 d_{S B}}}
\end{array}\right.
$$

where $n_{b, e f}$ is the effective number of fasteners connecting the angle to the glulam beam in the direction parallel to the grain $(Z$ axis $), n_{b}$ is the number of bolts in the direction parallel to the width of the beam ( $X$ axis), and $\gamma_{M}$ is the material safety factor . 
Finally, the overall joint yield resistance will be governed by the attainment of yielding in the Hollow-bolt at $F_{T, R d}$, or the formation of a mechanism in the tensioned region of the long bolt-timber assemblage (at $F_{v, \text { conf } 1}$ ). Therefore, in order to estimate the connection yield capacity, the following equation can be used:

$$
M_{y, \text { angle }}=\min \left\{\begin{array}{l}
F_{T, R d} \cdot h_{g l} \\
F_{v, \text { conf } 1} \cdot h_{g l}
\end{array}\right.
$$

where $h_{g l}$ is is the height of the glulam beam.

\subsubsection{Bolt-row Shear Failure}

The formation of a plastic mechanism involving significant plastic deformations in the timber and long bolts, as described by the expressions presented above, constitutes a lower-bound estimate of the joint capacity. Nevertheless, these mechanisms are associated with a ductile failure mode with significant post-yield stiffness. Therefore, in some circumstances it may be necessary to calculate the overall ultimate strength of the connection associated with the brittle shear bolt-row failure as observed in Specimens S1. In such cases, the shear capacity $\left(F_{\text {shear }}\right)$ of the tensile region of the beam can be determined from the shearing force developed in the failure plane shown in grey in Figure 20 such that:

$$
F_{\text {shear }}=2 \cdot n_{s, p l} \cdot \frac{\sigma_{v k}}{\gamma_{M}} \cdot l_{e f 1} \cdot h_{e f}
$$

with an effective height $h_{e f}$ dependent on the failure mode governing the plastic deformation of the joint as discussed above. Therefore:

$$
h_{e f}=\left\{\begin{array}{l}
2 \sqrt{\frac{M_{y, R k}}{\sigma_{11, e m b, k} \cdot d}}, \text { if } \mathrm{Eq}(7.5) \text { governs } \\
h_{g l}, \text { if } \mathrm{Eq}(7.6) \text { or } \mathrm{Eq}(7.7) \text { govern }
\end{array}\right.
$$

where, $l_{e f 1}$ is the effective length, $\sigma_{v, k}$ is the characteristic shear strength of glulam and $n_{s, p l}$ is the number of bolt-rows. Hence the moment capacity at ultimate associated with brittle shear failure can be defined as:

$$
M_{\text {shear }}=F_{\text {shear }} \cdot h_{\text {gl }}
$$




\subsection{Capacity estimation of Type 2 connections}

3

4

This type of connection can experience the following two fundamental failure modes: a) bolt yielding and/or bolt embedment into the timber beam, and b) bolt-row plug shear. In addition, the increased capacity due to yielding of reinforcing screws and the effects of adding a wedge angle should also be included. In this section, expressions for the evaluation of timber beamto-steel column connection stiffness and capacity are presented below. The section starts by introducing aspects of the force distribution in bolt-groups considering the possibility of boltrow plug shear and continues with the presentation of component-based expressions for the estimation of the connection capacity. Finally, considerations necessary for the inclusion of the effects of wedge angles or reinforcing screws are discussed.

\subsubsection{Force distribution in bolt-groups}

Figure 21 depicts a Type 2 connection under a generalized loading case expressed in terms of a moment $M_{d}$ and a set of vertical $F_{V}$ and horizontal $F_{H}$ forces where $\mathrm{C}$ denotes the geometric centre of the bolt-group. It is apparent from Figure 21 that Bolt-1 will experience the largest demand and hence will be determinant for the joint overall capacity estimations. If, as is the case for the connections examined herein, no significant external axial actions are applied on the joint, $F_{H}$ becomes negligible. Besides, when a wedge angle is inserted at the bottom of the beam, additional compressive stresses are developed in that region as illustrated in Figure 21. These will result in a re-configuration of forces within the joint that moves the point of rotation towards the bottom corner of the timber beam, as discussed above, hence increasing further the distance between the point of rotation and Bolt- 1 which continues to be the most critical fastener of the group.

The force taken by Bolt-1 $\left(F_{m, d, \max }\right)$ acts in a direction perpendicular to the vector $r_{\max }$ that defines the position of Bolt-1 with respect to the point of rotation C (e.g. the centroid of the bolt-group in the absence of a bottom wedge angle). Since Bolt-1 resists the largest force of all bolts in the group, it can be assumed that the corresponding horizontal bolt-row will be more prone to bolt row split failure than the others [29]. In this case, the total effective horizontal force $F_{d, H, \text { row } 1}$ acting on Bolt Row-1 can be expressed as:

$$
F_{d, H, \text { row } 1}=F_{m, d, \max , h} \cdot n_{\text {row } 1, e f}
$$


2 with,

$$
n_{\text {row } 1, e f}=\min \left\{\begin{array}{l}
n_{\text {row } 1} \\
n_{\text {row } 1}^{0.9} \sqrt[4]{\frac{c}{13 d}}
\end{array}\right.
$$

where $F_{m, d, \max , h}$ is the horizontal component of the force acting on Bolt-1, $n_{\text {row } 1}$ is the number of bolts in the direction parallel to the grain, and $c$ is the spacing between bolts as shown in Figure 4.

Form the above discussion, it follows that the expression relating the total effective horizontal force $F_{d, H, \text { row } 1}$ with the force $F_{m, d, \max }$ acting on Bolt-1 can be defined as:

$$
F_{m, d, \max }=F_{d, H, \text { row } 1} \cdot \frac{r_{\max }}{y_{1} \cdot n_{\text {row } 1, e f}}
$$

And the moment of the connection $\left(M_{d}\right)$ can be obtained as:

$$
M_{d}=\frac{F_{m, d, \max }}{r_{\max }} \cdot D
$$

where $y_{1}$ is the vertical distance between Bolt- 1 and the centre of rotation, and $D$ is the summation of all fasteners radii $r_{i}, i \in[1, n]$ squared.

\subsubsection{T-stub capacity}

The load-carrying capacity of the slotted-in T-stub can be estimated on the basis of the critical force acting on Bolt-1 $\left(F_{m, d, \max , h, k}\right)$ as discussed above. To this end, the expressions suggested in Chapter 8.2.3 of Eurocode 5 [21] can be employed such that:

$$
F_{m, d, m a x, h . k}=\min \left\{\begin{array}{l}
\sigma_{11, e m b, k} \cdot t_{1} \cdot d_{S B} \\
\sigma_{11, e m b, k} \cdot t_{1} \cdot d_{S B}\left[\sqrt{2+\frac{4 \cdot M_{y . R k}}{\sigma_{11, e m b} \cdot t_{1}^{2} \cdot d_{S B}}}-1\right]+\frac{F_{a x . R k}}{4} \\
2.3 \sqrt{2 \cdot M_{y \cdot R k} \cdot \sigma_{11, e m b, k} \cdot d_{S B}}+\frac{F_{a x . R k}}{4}
\end{array}\right.
$$

where $\sigma_{11, e m b, k}$ is the characteristic embedment strength parallel to the grain in MPa, $t_{1}$ is the distance parallel to the width of the beam between the side of the beam to the inserted metal plate in mm, and $M_{y \cdot R k}$ and $F_{a x . R k}$ are the characteristic yield moment of the bolt in $\mathrm{kNmm}$ 
and its withdrawal capacity in $\mathrm{kN}$, respectively.

The moment capacity $M_{d, y}$ of the slotted-in T-stub can be determined from the following expression

$$
M_{d, y}=F_{m, d, \max , h, k} \cdot \frac{D}{y_{1}}
$$

where $y_{1}$ is the vertical distance between Bolt- 1 and the centre of rotation $\mathrm{C}$, and $D$ is the summation of all fasteners radii $r_{i}, i \in[1,20]$ squared. A material safety factor, $\gamma_{M}$, can be employed for conservative capacity estimations.

\subsubsection{Bolt-row Plug Shear Failure}

The capacity of the connection associated with plug shear failure $\left(F_{\text {shear_limit }}\right)$ on the plane containing the top bolt-row (Bolt row-1 in Figure 21) can be estimated on the basis of the splitting resistance, as suggested by Porteous and Kermani [29]. Therefore:

$$
F_{\text {Shear_limit }}=\frac{2}{3} \cdot \frac{1}{\gamma_{M}}\left(w_{b}-t_{T s t u b}\right) \cdot l_{e f} \cdot \sigma_{v, k}
$$

with

$$
l_{e f}=b+\left(n_{\text {row } 1}-1\right)(c-d)-\frac{d}{2}
$$

where $w_{b}$ is the width of the glulam beam, $t_{T s t u b}$ is the thickness of the metallic plate inserted into the beam, $l_{e f}$ is the effective depth and $\sigma_{v, k}$ is the characteristic shear strength of glulam. Finally, the moment capacity for plug shear failure $\left(M_{d, P S}\right)$ takes the form:

$$
M_{d, P S}=F_{\text {shear_limit }} \cdot \frac{D}{y_{1} \cdot n_{\text {row } 1, e f}}
$$

\subsubsection{Contribution of reinforcing screws}

In addition to the T-stub capacity considerations described above, the load carrying capacity of Type 2 Connections with reinforcing screws will also depend on the additional loadcarrying capacity contributed by them. Figure 22 shows the forces developed on one side of Bolt-1.

By establishing equilibrium conditions on the system of forces represented in Figure 22, the reaction forces $F_{\text {screw } 1}$ and $F_{\text {screw } 2}$ can be found as:

$$
F_{\text {screw } 1}=\frac{F_{m, d, \max , h}}{2_{23}} \frac{\left(\mathrm{f}+\mathrm{m}-{ }^{w_{b} / 6}\right)}{\mathrm{f}}
$$


and

$$
F_{\text {screw } 2}=\frac{F_{m, d, \max , h}}{2} \frac{\left(w_{b} / 6-\mathrm{m}\right)}{\mathrm{f}}
$$

6

In the case where two adjacent bolts are reinforced by one screw, six possible failure modes should be considered, and the strength associated with screw failure, $R_{V E}$, will be $[30,31]$ :

$$
R_{V E}=\min \left[R_{1}, R_{2}, R_{3}, R_{4}, R_{5}, R_{6}\right]
$$

with

$$
R_{1}=0.5 \cdot \sigma_{e m b} \cdot d_{s} \cdot l_{s}
$$

$R_{2}=0.5 \cdot \sigma_{e m b} \cdot d_{s} \cdot l_{s} \cdot\left[\sqrt{\frac{16 \cdot M_{y, s}}{\sigma_{e m b} \cdot d_{s} \cdot l_{s}^{2}}+2\left(\frac{e}{l_{s}}-1\right)^{2}}+\frac{2 e}{l_{s}}-1\right]$

$$
R_{3}=0.5 \cdot \sigma_{e m b} \cdot d_{s} \cdot e+4 \sqrt{M_{y, s} \cdot \sigma_{e m b} \cdot d_{s}}
$$

$R_{4}=4 \sqrt{M_{y, s} \cdot \sigma_{e m b} \cdot d_{s}}$

$R_{5}=0.5 \cdot \sigma_{e m b} \cdot d_{s} \cdot l_{s} \cdot\left[\sqrt{\frac{16 \cdot M_{y, s}}{\sigma_{e m b} \cdot d_{s} \cdot l_{s}^{2}}+2\left(\frac{e}{l_{s}}-1\right)^{2}}+4 \sqrt{\frac{M_{y, s}}{\sigma_{e m b} \cdot d_{s} \cdot l_{s}^{2}}}+\frac{e}{l_{s}}-1\right]$

$R_{6}=0.5 \cdot \sigma_{e m b} \cdot d_{s} \cdot l_{s} \cdot\left[\sqrt{\frac{8 \cdot M_{y, s}}{\sigma_{e m b} \cdot d_{s} \cdot l_{s}^{2}}+\left(\frac{e}{l_{s}}-1\right)^{2}}-\frac{e}{l_{s}}+1\right]$

where $\sigma_{e m b}$ is the is the embedment stress in MPa, $d_{s}$ is the diameter of the screw in mm, $l_{s}$ is the length of the screw in mm, $M_{y, s}$ is the yield moment of the screw in Nmm, and $e$ is the spacing between the bolts in mm, as shown in Figure 4.

In addition, two different scenarios have to be examined. The first scenario considers bolts yielding before the capacity of screws is reached, $F_{\text {screw } 1}<R_{V E}$. In this case, the horizontal force acting in Bolt row-1 will be:

$$
F_{d, H, \text { row } 1}=F_{m, d, \max , h} \cdot n_{\text {row } 1, \text { ef }}+n_{\text {row } 1, \text { ef }}\left(2 F_{\text {screw } 1}+2 F_{\text {screw } 2}\right)
$$


1 And combining Equations (29) and (47) results in:

2

3

4

$$
F_{m, d, \max }=\left(F_{m, d, \max , h}+2 F_{\text {screw } 1}+2 F_{\text {screw } 2}\right) \frac{r_{\text {max }}}{y 1}
$$

Alternatively, the second scenario involves the screws yielding before the capacity of the bolts is reached, $F_{\text {screw } 1} \geq R_{V E}$. Hence, the force $F_{m, d, \max , h}$ transmitted to the bolts can be determined by rearranging Equation (38) and assuming $F_{\text {screw } 1}=R_{V E}$ such that:

$$
F_{m, d, \max , h}=\frac{2 \cdot \mathrm{f} \cdot R_{V E}}{\left(\mathrm{f}+\mathrm{m}-{ }^{w_{b}} / 6\right)}
$$

Consequently, by combining Equations (29) and (47), the force resisted by Bolt-1 can be estimated as:

$$
F_{m, d, \max }=\left(F_{m, d, \max , h}+2 R_{V E}+2 F_{\text {screw } 2}\right) \frac{r_{\text {max }}}{y_{1}}
$$

Finally, it is worth noting that the connection resistance to bolt-row plug shear failure is increased by the presence of screws and these effects can be incorporated by employing standard calculation procedures described in previous studies [29,30,31].

\subsubsection{Consideration of wedge angle effects}

Connections that incorporate a bottom wedge angle between the timber beam and the SHS column have an increased moment capacity with respect to connections that do not have that detail. In order to consider these effects in a simplified manner while ensuring conservative estimates, the total moment capacity $M_{T}$ of such connections can be idealised as the summation of independent contributions of the original detail, $M_{\text {connection }}$, plus the moment increment associated with the wedge angle contribution, $M_{d, \text { angle }}$ :

$$
M_{T}=M_{\text {connection }}+M_{\text {, angle }}
$$

where $M_{\text {connection }}$ can be obtained by means of the corresponding expressions presented above, with due consideration of the modified location of the point of rotation, as discussed in previous sections. On the other hand, the moment capacity contribution of the wedge angle can be calculated from the additional bearing resistance generated at the bottom of the beam:

$$
M_{d, \text { angle }}=\sigma_{c, 0, k} \cdot h_{A} \cdot\left(w_{b}-t_{T s t u b}\right) \cdot y_{A}
$$

where $\sigma_{c, 0, k}$ is the characteristic compression strength parallel to the direction of the grain, $h_{A}$ is the length of the smaller leg of the angle excluding its thickness, and $y_{A}$ is the distance 
1 between the centroid of the bolt group arrangement $(\mathrm{C})$ and the centroid of the bearing zone 2 (see Figure 21).

3

4 5

\subsection{Connection Stiffness}

\subsubsection{Type 1 Connections}

The initial stiffness of the top $\left(K_{\text {Top }}\right)$ and seat $\left(K_{\text {Bottom }}\right)$ angle components of Type 1 connections can be evaluated form the added contributions of the bearing stiffness of the column face $\left(K_{C F}\right)$, the Hollo-bolt axial stiffness $\left(K_{H B}\right)$ and the tension stiffness of the angle horizontal leg $\left(K_{t}\right)$ as:

$$
\begin{aligned}
& K_{\text {Top }}=\frac{1}{\frac{1}{K_{C F}}+\frac{1}{K_{H B}}+\frac{1}{K_{t}}} \\
& K_{\text {Bottom }}=\frac{1}{\frac{1}{K_{C F}}+\frac{1}{K_{t}}}
\end{aligned}
$$

where $K_{C F}, K_{t}$ and $K_{H B}$ can be taken from the corresponding expressions available from previous studies $[9,19]$. For simplicity, a pre-defined point of rotation can be assumed at the horizontal leg of the bottom angle for top and seat angle connections. The rotational stiffness $S_{\text {config1,init }}$ can be obtained by applying the following expression given by Pucinotti [32]:

$$
S_{\text {config1,init }}=\frac{h_{g l}^{2}}{\frac{1}{K_{\text {Top }}}+\frac{1}{K_{\text {Bottom }}}}
$$

\subsubsection{Type 2 Connections}

For Connection Type 2, the rotational stiffness, $S_{\text {config } 2}$, of the connection can be estimated following the suggestion of Porteous and Kermani [29] as:

$$
S_{\text {config } 2}=2 \cdot K_{\text {ser }} \cdot \sum_{i=1}^{n} r_{i}^{2}
$$

where, $K_{\text {ser }}$ is the slip modulus of each individual bolt in N/mm]:

$$
K_{\text {ser }}=\rho^{1.5} \cdot \frac{d}{23}
$$




\subsection{Comparative assessment}

Figures 23 and 24 present comparisons between the experimental moment-rotation curves and the estimations of stiffness and flexural strength obtained using the expressions presented above for Type 1 and Type 2 connections, respectively. It should be noted that, in order to provide a direct validation of the component-based expressions adopted, the experimentally obtained material values as described in Section 2 are considered. Similarly, all material safety factors are assumed as unity for the purpose of these comparisons. A nominal shear strength value of $3.2 \mathrm{MPa}$ is employed. Also, the ideal locations of the point of rotation calculated as described in Section 2 are adopted.

It is clear from Figures 23 and 24 that the suggested component based approach provides reasonable representations of the stiffness and capacity in all cases. It can be observed from Figure 23 for Type 1 connections, that the initial yield is governed by formation of a plastic mechanism in the angle components for Specimen S2, while for specimen S1 the initial yield is governed by yielding of the blind-bolts. Also, Specimen S1 experienced an ultimate failure mode governed by bolt-row shear failure in the top tension region of the joint that can be conservatively estimated using Equation (25).

For the second connection type, presented in Figure 24, it is clear that the suggested component model offers a realistic and conservative estimate of the joint initial stiffness and yield moment capacity. In particular, in all cases the initial stiffness matches the experimental results with an accuracy of $\pm 10 \%$. However, Figures $24 \mathrm{a}$ and $24 \mathrm{~b}$ demonstrate that the moment capacity estimation for plug-shear failure $M_{d, P S}$ as described by Equation (37) overestimates the fracture capacity of the connections by $15 \%$ and $28 \%$ respectively. Likewise, the assumptions of rigid motion and equivalent bolt-row areas for the angle wedge, as explained above, seem to provide an adequate basis for estimating the point of rotation of the connection.

\section{Practical Application}

The experimental and numerical results and observations presented in this paper provide essential data for future parametric studies that would extend the range of dimensions and configurations examined in this study. Nevertheless, it should be noted that, in the light of codified connection classification conventions [20], the hybrid connection configurations 
considered herein offer reasonable levels of stiffness and capacity within the range of typical semi-rigid connections. However, these considerations are evidently dependent on the section of the beam attached to the connection. For example, Eurocode 3 [20] classifies connections based on their normalized stiffness (in relation to the beam stiffness) and normalized capacity (in relation to the beam capacity). By considering possible practical ranges of glulam beams e.g. $[6000,9000 \mathrm{~mm}]$ the normalized stiffness of Type 1 connections ranges from 7.2 and 7.3 $\mathrm{kNm} / \mathrm{mrad}$ which classifies them as nominally pinned. On the other hand, Type 2 connections would have normalized stiffness in the order of $2 \mathrm{kNm} / \mathrm{mrad}$ which lies firmly within the semi-rigid range.

It should be noted that in addition to the estimations of connection stiffness and capacity, the joint ductility is a key design consideration. In that regard, the connections examined herein exhibited failure rotations exceeding $57 \mathrm{mrad}$ for unreinforced configurations. These ultimate rotation levels are well above normal requirements for monotonic or cyclic loading conditions. Also, these ductility levels were significantly influenced by the presence of reinforcing screws in Type 2 connections which prevented brittle bolt-row plug shear failure and extended the rotation capacity of the connection beyond the reach of the actuator stroke at 130 mrad.

\section{Conclusions}

The flexural behaviour of novel hybrid bolted connections between Glulam timber beams and tubular steel columns has been studied by means of experimental, numerical and simplified analytical models. Two different connection alternatives were examined involving top and seat angle details as well as slotted-in T-stub bolted configurations. An experimental programme comprising six monotonic tests on joints subjected to bending was described in detail. The main behavioural patterns were identified, and the key response characteristics such as stiffness, capacity and failure mechanism were discussed. The experimental results provided the necessary information for the validation and calibration of complementary finite element and simplified component-based models.

The failure mechanisms exhibited by top and seat blind-bolted connections were identified. Given the growing body of research on the influence of the characteristics of the tubular column face, angle component and blind bolt arrangement, this study focused on the interaction between the long bolt-angle assembly and the timber beam. When a stiffer angle 
was employed, higher forces were generated in the long bolt running parallel to the beam depth leading to localized shear failure in the wood.

In the case of slotted-in bolted connections, a detailed evaluation of the migration of the point of rotation was made based on continuous non-contact strain field measurements and Digital Image Correlation techniques. Two distinct stages were identified. Prior to $8.3 \mathrm{mrad}$ of joint rotation, a markedly horizontal displacement of the point of rotation was observed while a predominantly vertical migration of the point of rotation was recorded for larger joint rotations. A simplified calculation procedure for the estimation of the location of the point of rotation, based on the use of an equivalent row of bolts with equal area to account for the effects of the wedge angle, was proposed.

Two alternatives of joint reinforcement were examined in the case of T-stub slotted-in boltgroup details, namely: the use of reinforcing screws against wood splitting, and the provision of a bottom wedge angle to enhance the joint strength. It was illustrated that the screws can significantly increase the connection failure moment, by around $36 \%$, through a successful prevention of wood splitting, whereas the incorporation of a wedge bottom angle reduces the effects of instantaneous bolt slippage and significantly enhances the ultimate connection capacity in excess of $50 \%$. The range of stiffness and capacity obtained from these specimens indicate that for typical Glulam beam configurations, the proposed detail could be designed as a semi-rigid connection with significant transfer of moment to the columns.

A three-dimensional finite element model was developed to simulate the response of the hybrid timber beam-to-steel column connections considered in this investigation. The recently proposed modified foundation model was employed to incorporate the effects of localized wood crushing due to fastener embedment. A detailed explanation of the modelling approach and necessary parameters was presented. The results obtained by means of this FE representation compared well with the experimental response. Although the precise definition of a shear failure criterion was not implemented, the agreement between the FE simulations and the test results showed that the proposed FE models can capture the actual response of both connection types. Finally, component based expressions for the estimation of connection stiffness and capacity under bending have been proposed and validated. These expressions were found to produce reliable and mostly conservative estimates of the connection stiffness and yield capacity. 


\section{References}

[1] Kim JW, Lee CH, Kang THK. Shearhead reinforcement for concrete slab to concretefilled tube column connections. ACI Struct J 2014. 111(3): 629-638.

[2] D.V. Bompa, A.Y. Elghazouli. Ultimate shear behaviour of hybrid reinforced concrete beam-to-steel column assemblages. Engineering Structures, Vol. 101, pp. 318-336, 2015

[3] C. Dickof, S.Stiemer, M. Bezabeh and S. Tesfamariam. CLT-Steel Hybrid System: Ductility and Overstrength Values Based on Static Pushover Analysis. Journal of Performance of Constructed Facilities, Vol. 28, issue 6, pp. A4014012, 2014.

[4] K. A. Okutu, B. Davison, J. Carr, Steel-Timber Hybrid Floors - Lowering the Embodied Impacts of Steel Frame Multi-Storey Construction, to be presented at the 7th European conference on Steel and Composite Structures, Naples, September 10-12, 2014,

[5] Cate St. Hill, Banyan Wharf, Regent's Canal conservation area by Hawkins Brown, 26/06/2013, available at: http://www.bdonline.co.uk/banyan-wharf-regent $\% \mathrm{E} 2 \% 80 \% 99 \mathrm{~s}$ canal-conservation-area-by-hawkins-brown/5057697.article, last accessed: 15/12/2015.

[6] Architect magazine, UBC Earth Systems Science Building (ESSB), 11/03/2014, available at: http://www.architectmagazine.com/project-gallery/ubc-earth-systems-science-buildingessb. last accessed: 15/12/2015.

[7] R. Bainbridge and C. Mettem. A review of moment-resistant structural timber connections. Proceedings of the Institute of Civil Engineers, Journals Structures and Buildings, Vol. 128, issue 4, pp. 323-331, 1998.

[8] C. Málaga-Chuquitaype, A. Y. Elghazouli. Behaviour of combined channel/angle connections to tubular columns under monotonic and cyclic loading, Engineering Structures, Vol. 32, pp. 1600-1616, 2010.

[9] A. Y. Elghazouli, C. Málaga-Chuquitaype, J. M. Castro and A. H. Orton. Experimental Monotonic and Cyclic Behaviour of Blind-Bolted Angle Connections. Engineering Structures, Vol. 31, pp. 2540-2553, 2009.

[10] Y. Liu, C. Málaga-Chuquitaype and A. Y. Elghazouli. Behaviour of beam-to-tubular column angle connections under shear loads, Engineering Structures, Vol. 31, pp. 434-456, 2012.

[11] Z.Y. Wang, Q.Y. Wang. Yield and ultimate strengths determination of a blind bolted endplate connection to square hollow section column, Engineering Structures, Vol. 111, pp. 345-369, 2015.

[12] R.O. Foschi, Load-slip characteristics of nails, Wood Science, Vol.7, pp. 69-76, 1974.

[13] J.P. Hong, Three-dimensional nonlinear finite element model for single and multiple dowel-type wood connections, PhD thesis, Program of Forestry, University of British Columbia, Canada, 2007.

[14] V. Karagiannis, C. Málaga-Chuquitaype and A. Y. Elghazouli. Modified foundation modelling of dowel embedment in glulam connection. Construction and Building Materials, Vol. 102, Part 2, pp. 1168-1179, 2016. 
[15] V. Karagiannis. Structural Response of Hybrid Steel-Timber Systems. [Ph.D Thesis]. Imperial College London, 2006.

[16] Y. Liu, C. Málaga-Chuquitaype and A. Y. Elghazouli. Response and component characterisation of semi-rigid connections to tubular columns under axial loads. Engineering Structures, Vol. 41, pp. 510-532, 2012.

[17] Lindapter International Ltd. Type HB hollo-bolt for blind bolt connection to structural steel and structural tubes. UK: Lindapter International Ltd.; 1995.

[18] A. Elamin, W. Tizani and M. Mahmood. Bolts gauge effect on the face bending behaviour of concrete-filled hollow section for hollo-bolted connections. Applied Mechanics and Material, Vol. 773-774, pp. 105-109, 2015

[19] C. Málaga-Chuquitaype and A. Y. Elghazouli. Component-based Mechanical Models for Blind-bolted Angle Connections. Engineering Structures, Vol.32, pp. 3048-3067, 2010.

[20] CEN.EN 1993-1-8. Eurocode 3: Design of Steel Structures, Part 1-8: Design of Joints, 2005

[21] CEN.EN 1995-1-1. Eurocode 5: Design of Timber Structures, Part 1-1: GeneralCommon rules and rules for buildings, 2004

[22] European Standard CEN EN 384:2010. Structural timber - Determination of characteristic values of mechanical properties and density. July 2010.

[23] LaVision UK Ltd. www.lavisionuk.com. [Last accessed 15/05/2015].

[24] ABAQUS, ABAQUS theory manual, version 5.4. Hibbit, Karlsson and Sorensen Inc., 1994.

[25] B. H. Xu, A. Bouchaïr, M. Taazount and E. J. Vega. Numerical and experimental analyses of multiple-dowel steel-to-timber joints in tension perpendicular to grain. Engineering Structures, Vol. 31, issue 10, pp. 2357-2367, 2009.

[26] European Standard CEN EN 338:2009. Structural Structures - Strength Classes. October 2009.

[27] I. Smith, Coefficient of friction values applicable to contact surfaces between mild steel connectors such as bolts and dry European white wood, Journal of the Institute of Wood Science, Vol. 9, pp. 229-234, 1983.

[28] C. Faella, V. Piluso, G. Rizzano. Structural steel semi-rigid connections: theory, design and software. Florida (USA): CRC Press; 2000.

[29] J. Porteous and A. kermani, Structural Timber Design to Eurocode 5. Blackwell Publishing. $1^{\text {st }}$ edition, 2007, ISBN-13: 978-1-4051-4638-8.

[30] D. Lathuillière, L. Bléron, T. Descamps, J.-F. Bocquet. Reinforcement of dowel type conenctions. Construction and Building Materials, Vol.97, pp. 48-54, 2015.

[31] I. Bejtka, HJ Blass. Self-tapping screws as reinforcements in connections with doweltype fasteners. Proceedings of International Council for Building. Research and Innovation Working 18, vol. 38, Paper 38-7-4. Germany, 2005

[32] R. Puccinoti. Top-and-seat and web angle connections: Prediction via mechanical model. Journal of Construction Steel Research, Vol. 57, issue 6, pp. 663-696, 2001. 


\begin{tabular}{|cccccccc|}
\hline Reference & \multicolumn{6}{c|}{ Dimensions (as shown in Fig. 3) } \\
& $a^{\prime}$ & $b^{\prime}$ & $c^{\prime}$ & $d^{\prime}$ & $e^{\prime}$ & $f^{\prime}$ & $g^{\prime}$ \\
\hline S1 & 36 & 68 & 56 & 60 & 84 & 116 & 34 \\
& & & & & & & \\
S2 & 36 & 68 & 56 & 60 & 84 & 116 & 34 \\
\hline
\end{tabular}

Table 1. Summary of the two test specimens for Type 1 connections. Dimensions in mm. All Type 1 specimens employed 150x10 SHS steel columns, 140x405 Glulam beams and L200x150x15 steel angles.

\begin{tabular}{|cccccccc|}
\hline \multirow{2}{*}{ Reference } & $\begin{array}{c}\text { Angle } \\
\text { wedge }\end{array}$ & Screws & \multicolumn{4}{c|}{ Dim. (as shown in Fig. 4) } \\
& & & a & b & c & d & e \\
\cline { 4 - 8 } S3 & No & No & 20 & 80 & 50 & 35 & 52.5 \\
S4 & Yes & No & 10 & 90 & 50 & 35 & 52.5 \\
S5 & No & Yes & 20 & 80 & 50 & 35 & 52.5 \\
S6 & Yes & Yes & 10 & 90 & 50 & 35 & 52.5 \\
\hline
\end{tabular}

Table 2. Summary of the two test specimens for Type 2 connections. Dimensions in $\mathrm{mm}$. All Type 2 specimens employed 150x10 SHS steel columns and 140x280 Glulam beams while L200x60x12 angles were employed as wedged when indicated.

\begin{tabular}{|c|c|c|c|c|c|c|c|}
\hline \multirow[t]{2}{*}{$\begin{array}{l}\text { Mech. } \\
\text { Properties }\end{array}$} & \multirow{2}{*}{$\begin{array}{c}\text { Bending } \\
\text { Strength } \\
\\
\sigma_{b} \\
{[\mathrm{MPa}]}\end{array}$} & \multicolumn{2}{|c|}{$\begin{array}{l}\text { Compressive } \\
\text { Strength }\end{array}$} & \multicolumn{2}{|c|}{ Young's modulus } & \multirow{2}{*}{$\begin{array}{c}\begin{array}{c}\text { Shear } \\
\text { Modulus }\end{array} \\
\\
G_{12} \\
{[\mathrm{MPa}]}\end{array}$} & \multirow{2}{*}{$\begin{array}{c}\text { Density } \\
\\
\rho \\
{\left[\mathrm{kgm}^{-3}\right]}\end{array}$} \\
\hline & & $\begin{array}{c}\text { Parallel } \\
\sigma_{c, 0} \\
{[\mathrm{MPa}]}\end{array}$ & $\begin{array}{c}\text { Perpend. } \\
\sigma_{c, 90} \\
{[\mathrm{MPa}]}\end{array}$ & $\begin{array}{c}\text { Parallel } \\
E_{0} \\
{[\mathrm{MPa}]}\end{array}$ & $\begin{array}{c}\text { Perpend. } \\
E_{90} \\
{[\mathrm{MPa}]}\end{array}$ & & \\
\hline Average & 33.5 & 33.0 & 3.6 & 12110 & 430 & 917 & 431 \\
\hline $\operatorname{COV}[\%]$ & 9.5 & 6.9 & 8.9 & 8.8 & 5.1 & 63.6 & 3.5 \\
\hline
\end{tabular}

Table 3. Summary of the mechanical properties for glulam GL28h.

\begin{tabular}{|ccc|}
\hline Component & Yield Stress [Mpa] & Ultimate Stress [Mpa] \\
L 200 × 150 × 12 & 408 & 514 \\
L 200 $150 \times 15$ & 361 & 486 \\
SHS $150 \times 150 \times 10$ & 334 & 433 \\
\hline
\end{tabular}

Table 4. Material properties of steel angles and column. 


\begin{tabular}{|cc|cc|cc|}
\hline Reference & $\begin{array}{c}\text { Initial } \\
\text { Stiffness }\end{array}$ & $\begin{array}{c}\text { Yield } \\
\text { moment }\end{array}$ & $\begin{array}{c}\text { Rotation } \\
\text { at yield } \\
\text { moment }\end{array}$ & $\begin{array}{c}\text { Peak } \\
\text { moment } \\
\text { reached }\end{array}$ & $\begin{array}{c}\text { Rotation at } \\
\text { peak moment }\end{array}$ \\
\hline S1 & {$[\mathrm{kNm} / \mathrm{mrad}]$} & {$[\mathrm{kNm}]$} & {$[\mathrm{mrad}]$} & {$[\mathrm{kNm}]$} & {$[\mathrm{mrad}]$} \\
$\mathrm{S} 2$ & 7.3 & 19.1 & 5.9 & 48.8 & 90.1 \\
\hline
\end{tabular}

*The actuator stroke was reached before evident signs of joint failure.

Table 5. Summary of the test results for Type 1 connections.

6

$$
7
$$

\begin{tabular}{|l|c|c|c|}
\hline \multirow{2}{*}{ Properties } & \multicolumn{2}{|c|}{ Experimental data } & Estimated data \\
\cline { 2 - 4 } & $\mathrm{d}=12 \mathrm{~mm}$ & $\mathrm{~d}=16 \mathrm{~mm}$ & $\mathrm{~d}=10 \mathrm{~mm}$ \\
\hline$E_{1, E m b}$ & 376.0 & 1033.9 & 376.0 \\
\hline$E_{2, E m b}=E_{3, E m b}$ & 136.8 & 240.8 & 136.8 \\
\hline$\sigma_{11, E m b}$ & 29.4 & 29.6 & 29.3 \\
\hline$\sigma_{22, E m b}=\sigma_{33, E m b}$ & 14.7 & 14.6 & 14.8 \\
\hline
\end{tabular}

Table 7 - Estimated material properties for fastener diameter of $10 \mathrm{~mm}$.

\begin{tabular}{|c|c|c|c|}
\hline Parameter & $\mathrm{d}=12 \mathrm{~mm}$ & $\mathrm{~d}=16 \mathrm{~mm}$ & $\mathrm{~d}=10 \mathrm{~mm}$ \\
\hline$\beta_{1}$ & 6.27 & 2.28 & 8.27 \\
\hline$\beta_{2}$ & 5.51 & 3.13 & 6.70 \\
\hline
\end{tabular}




\begin{tabular}{|c|c|c|c|}
\hline Parameter & $\mathrm{d}=12 \mathrm{~mm}$ & $\mathrm{~d}=16 \mathrm{~mm}$ & $\mathrm{~d}=10 \mathrm{~mm}$ \\
\hline$\gamma_{1}$ & 14.67 & 14.60 & 11.22 \\
\hline$\gamma_{2}$ & 21.57 & 21.74 & 11.03 \\
\hline
\end{tabular}

Table 9 - Values for parameters $\gamma_{1}$ and $\gamma_{2}$. From [14]

2

3

4

5

6

7 


\section{Figures}

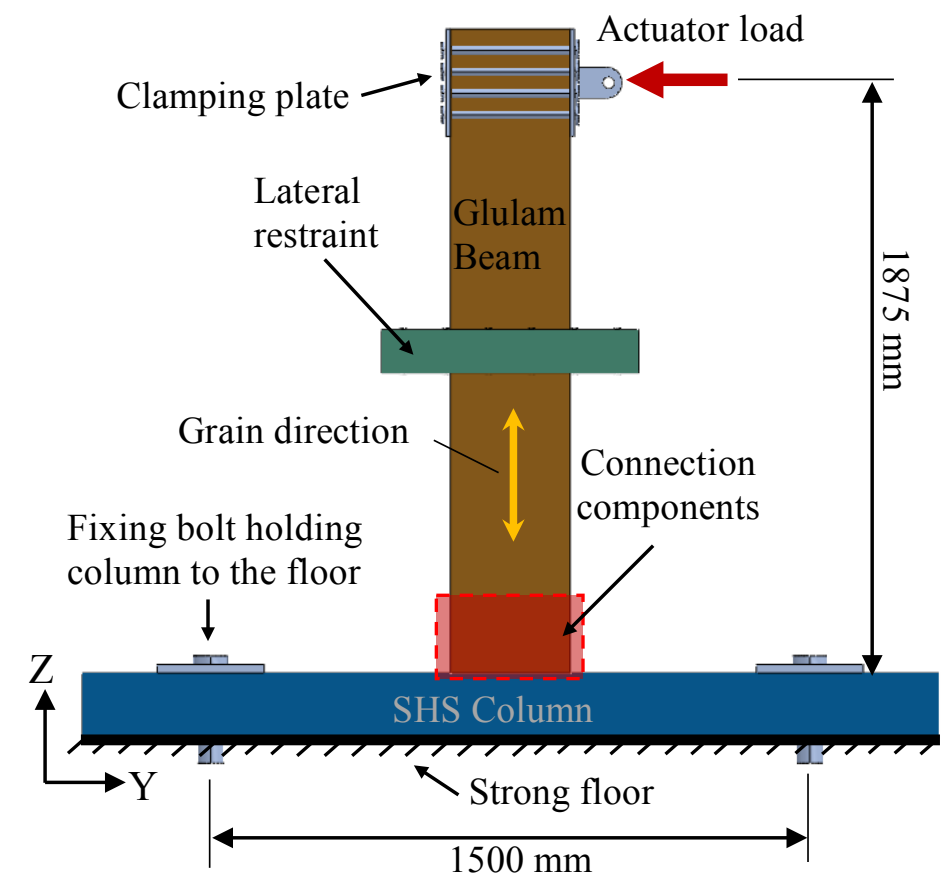

(a) Side view

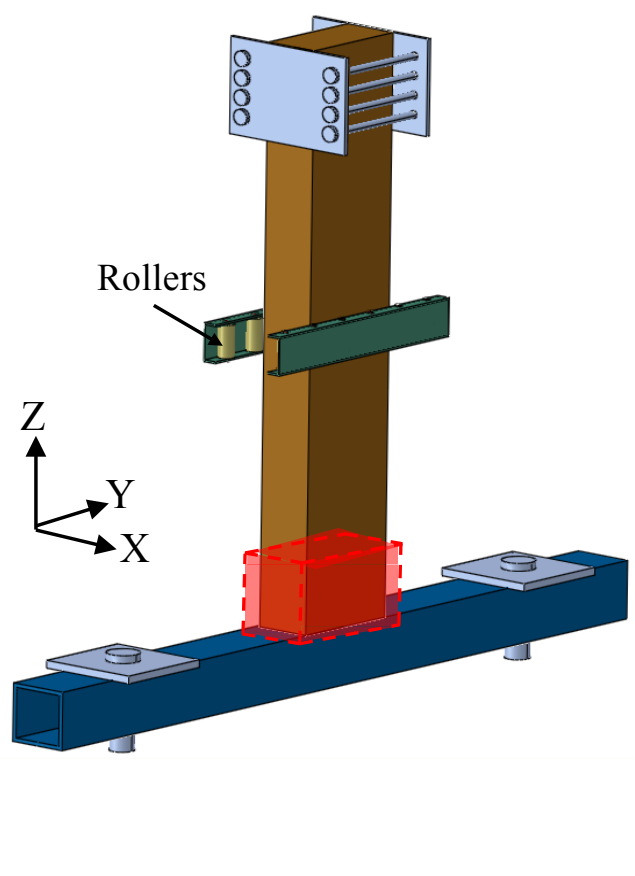

(b) Isometric view

Figure 1. Experimental set-up.

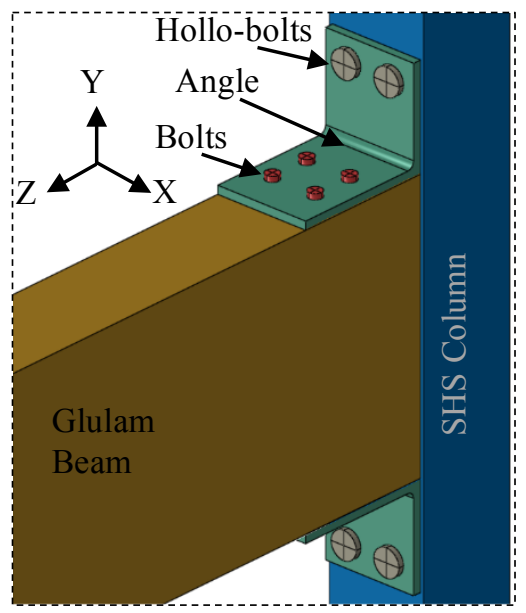

(a) Type 1

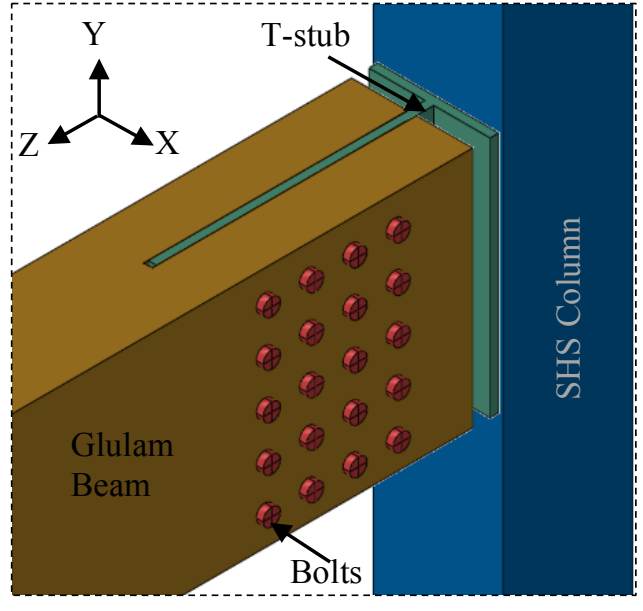

(b) Type 2

Figure 2. Isometric view of connection details. 


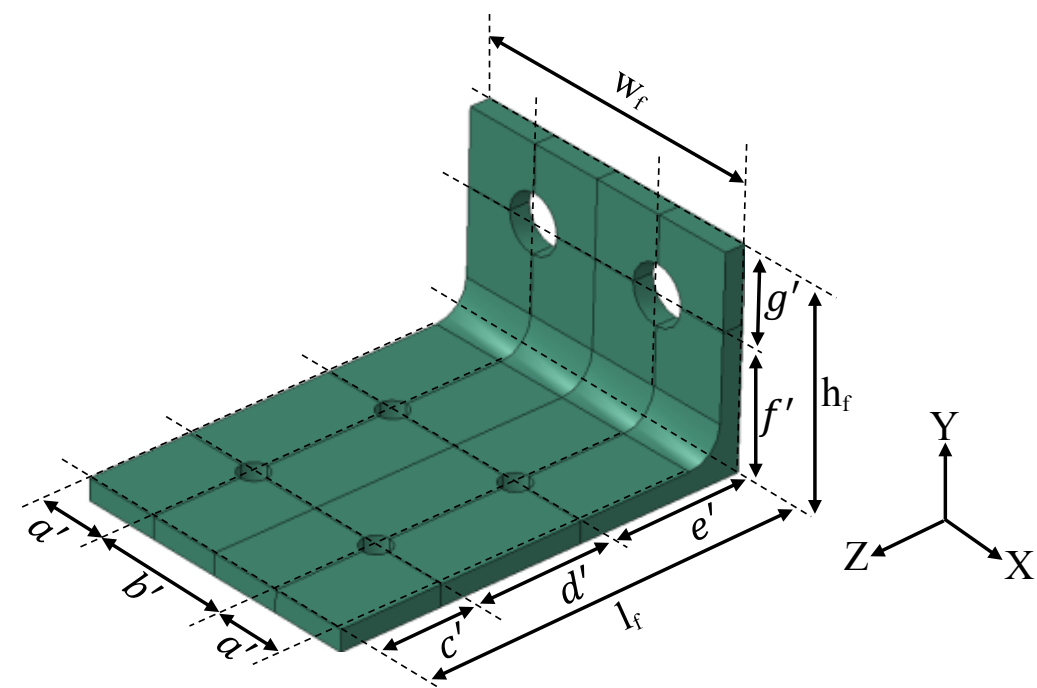

Figure 3. Angle nomenclature.

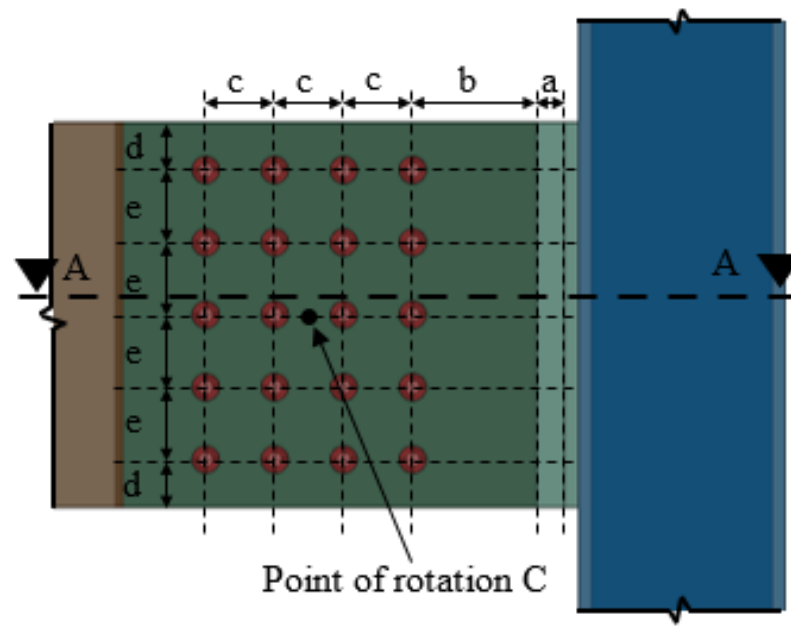

(a) $\mathrm{S} 3$

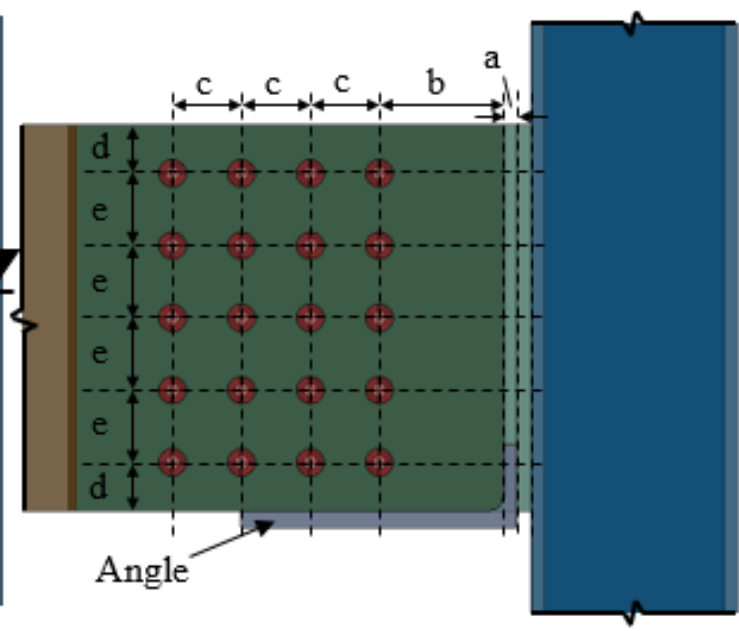

(b) $\mathrm{S} 4$

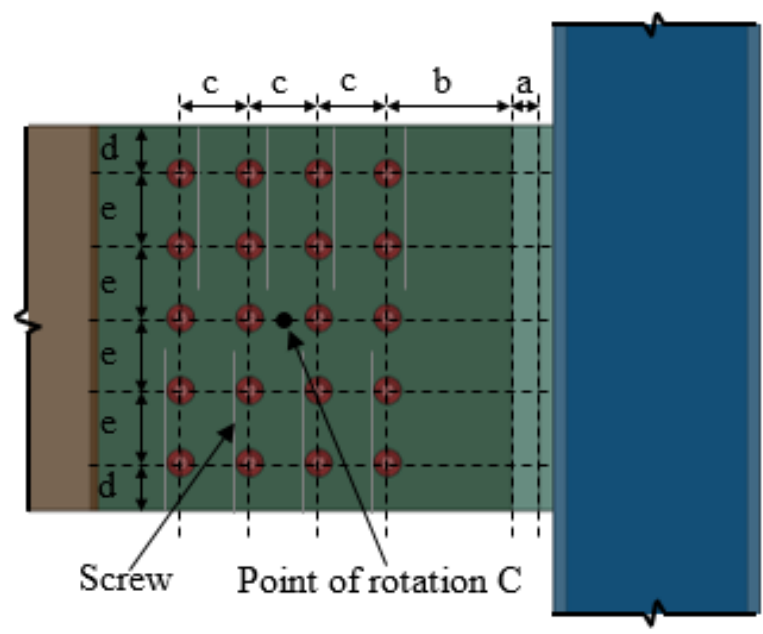

(c) $\mathrm{S} 5$

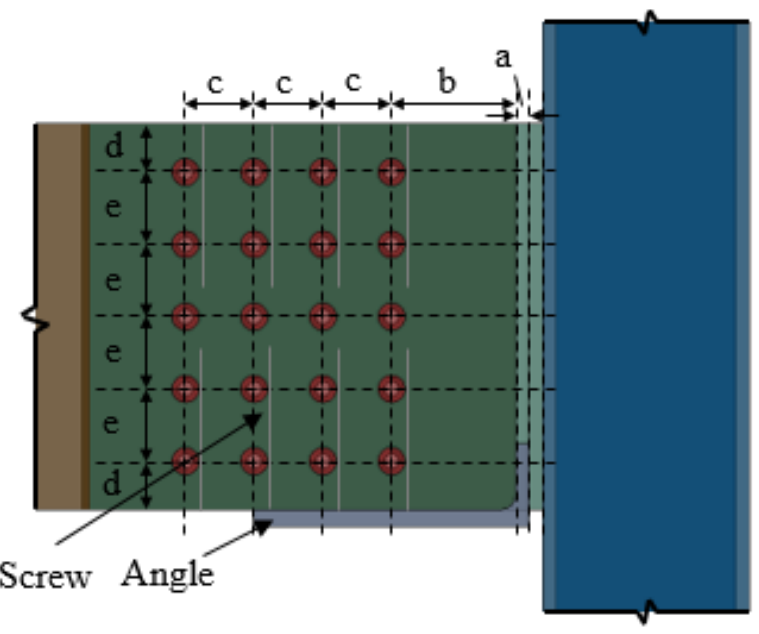

(d) $\mathrm{S} 6$

Figure 4. Details of connection Type 2. 


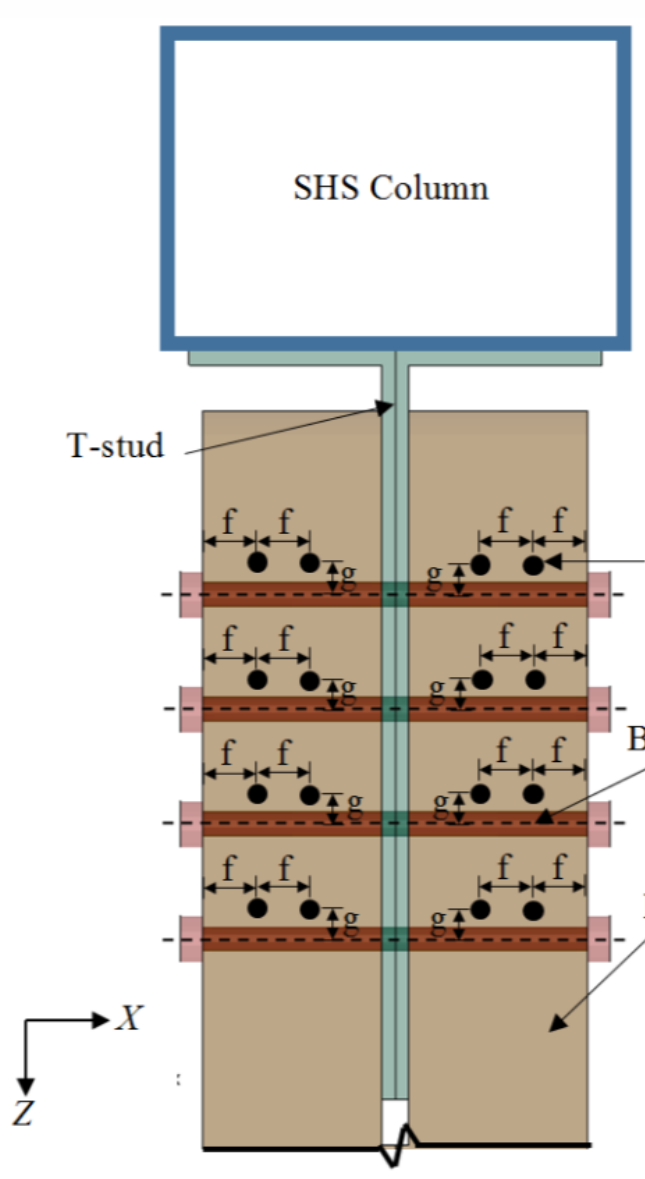

(a) Top view of connection prior to load application

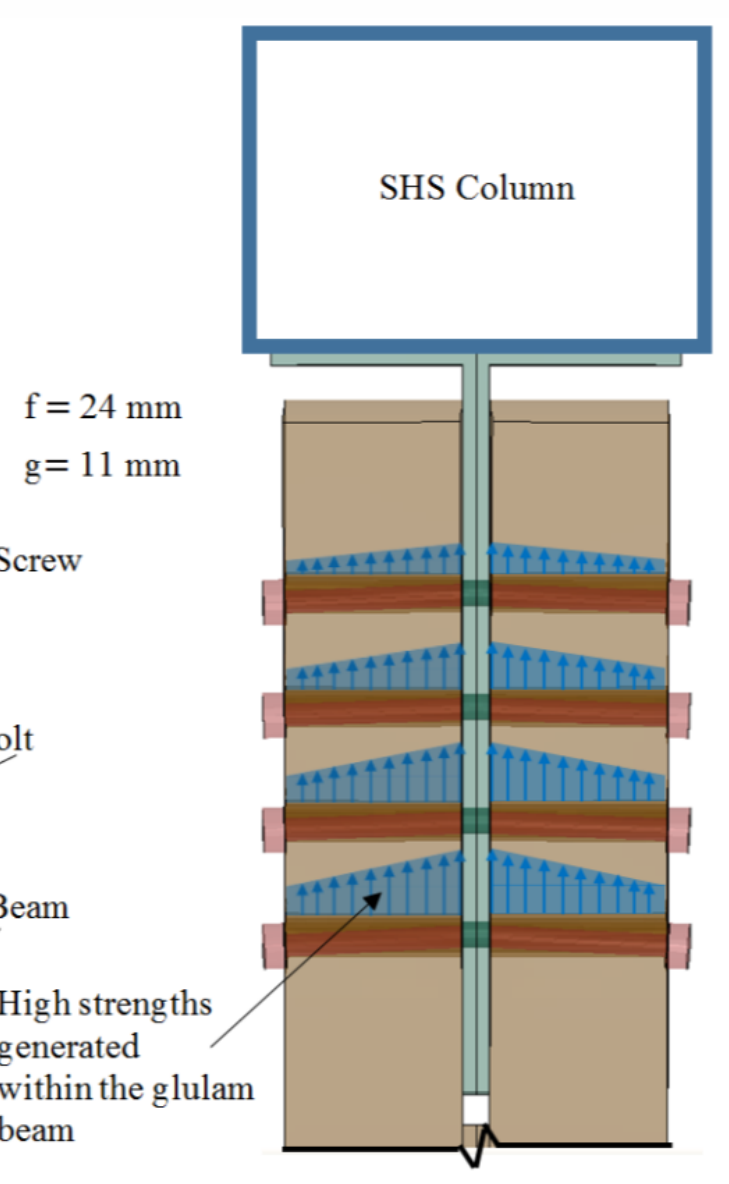

(b) Top view of connection after load application

Figure 5. Location of reinforcing screws in Specimens S5 and S6. (Plan view corresponding to Section A-A in Figure 4). 


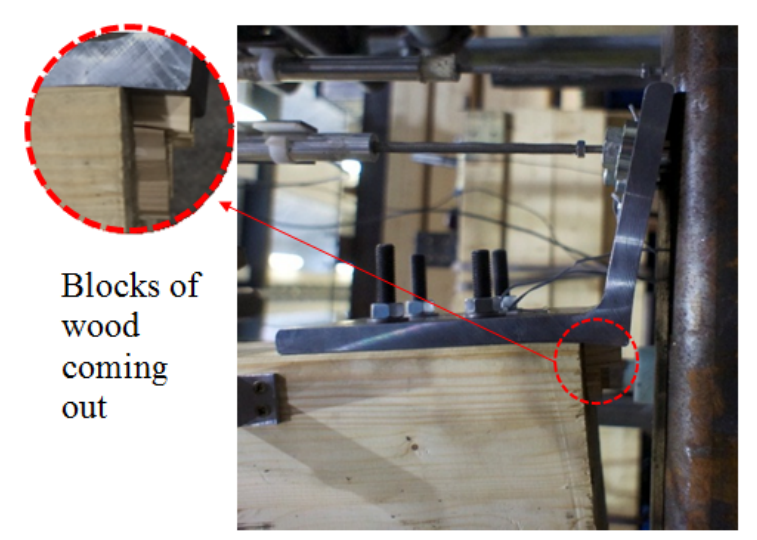

Top Angle

(a) Specimen $\mathrm{S} 1$

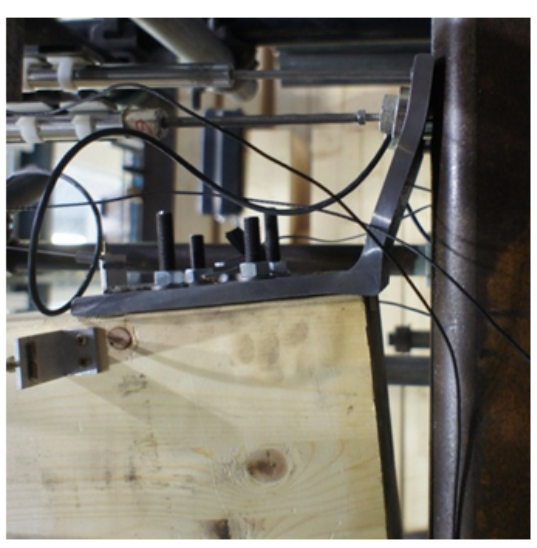

Top Angle

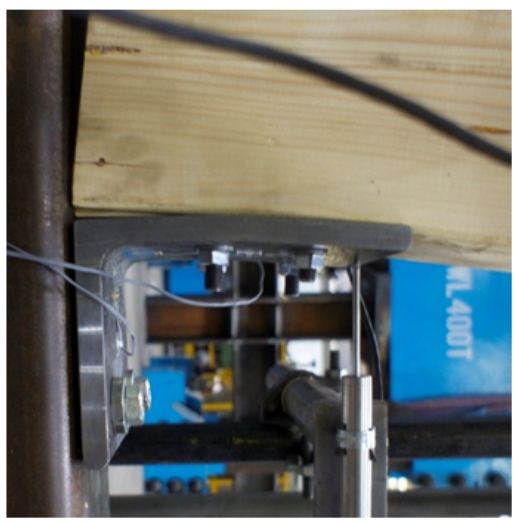

Bottom Angle

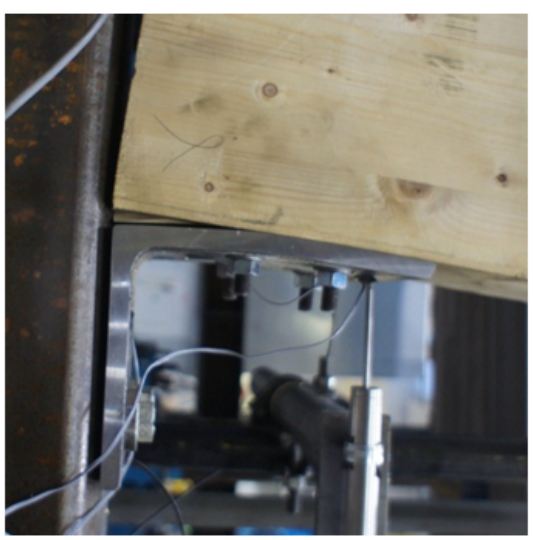

Bottom Angle

(b) Specimen S2

Figure 6. Failure modes of Type 1 connections.

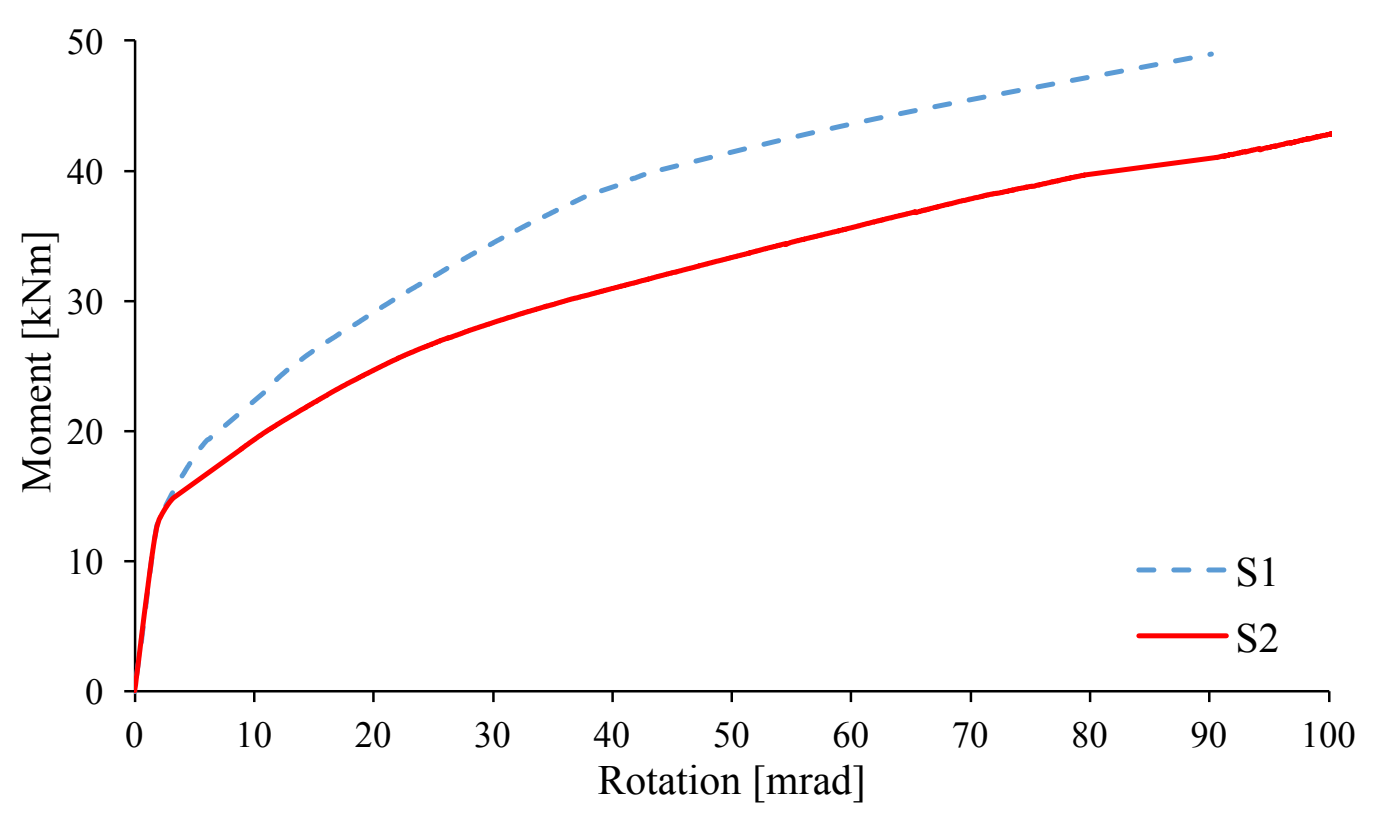

Figure 7. Moment-rotation relationships for Type 1 connections. 
1

2

3

4

5

6

7

8

9

11
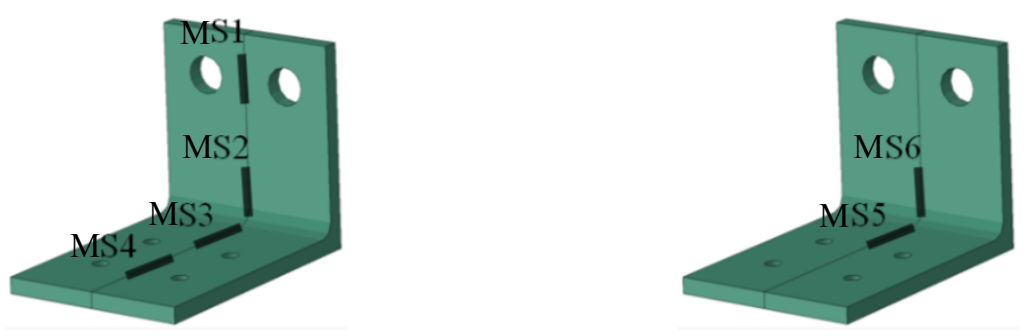

(a) Location of strain gauges
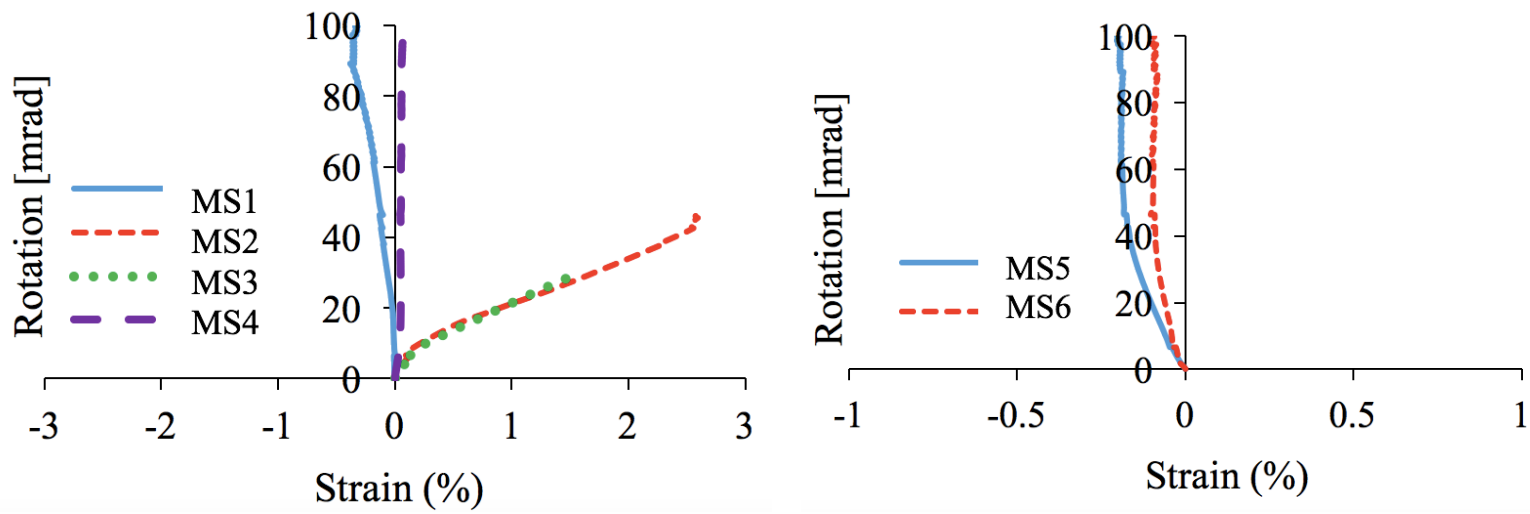

(b) Specimen S1
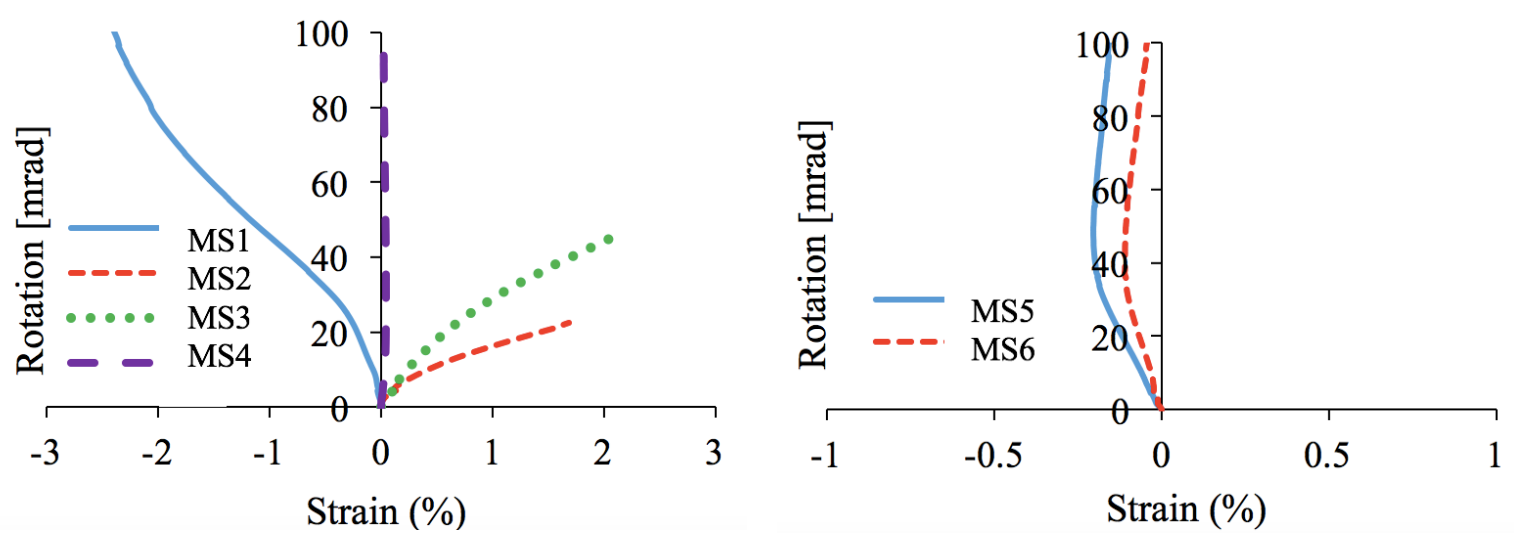

(c) Specimen S2

Figure 8. Measured strains in Type 1 connections. 


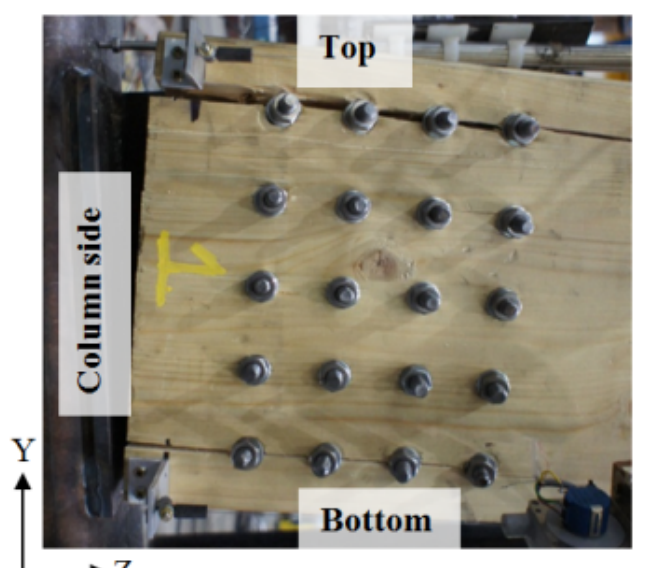

(a) $\mathrm{S} 3$

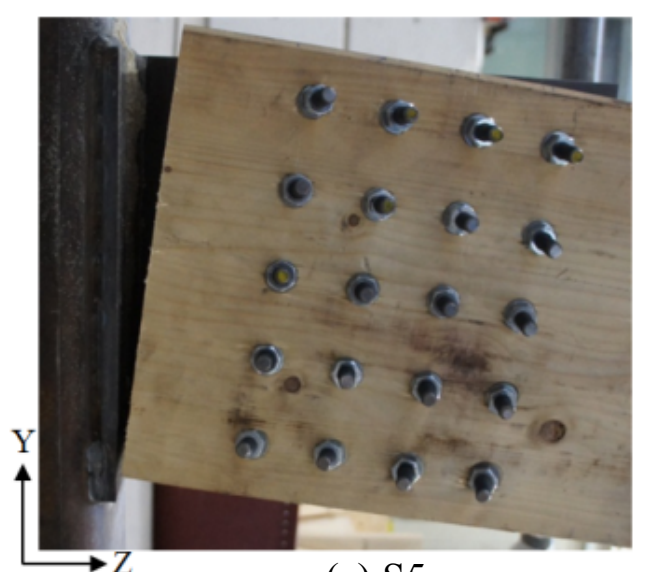

(c) $\mathrm{S} 5$

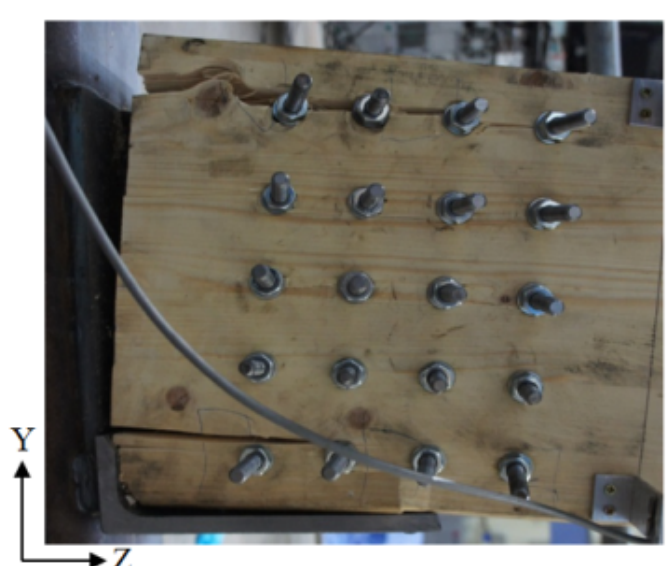

(b) $\mathrm{S} 4$

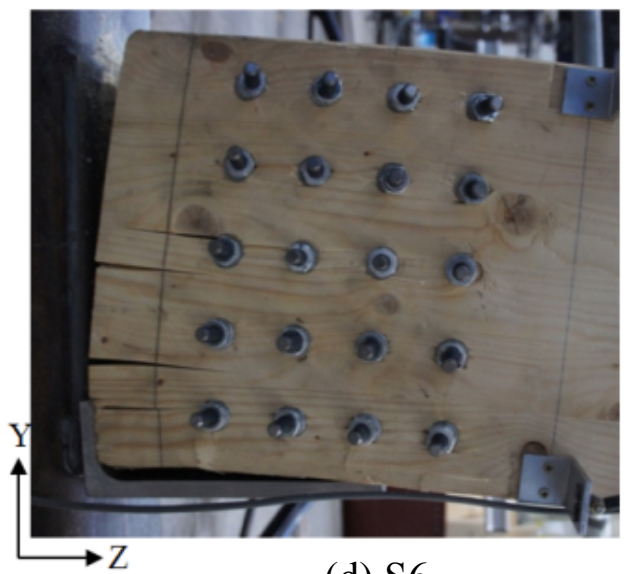

(d) $\mathrm{S} 6$

Figure 9. Failure modes of Type 2 connections at the end of test.

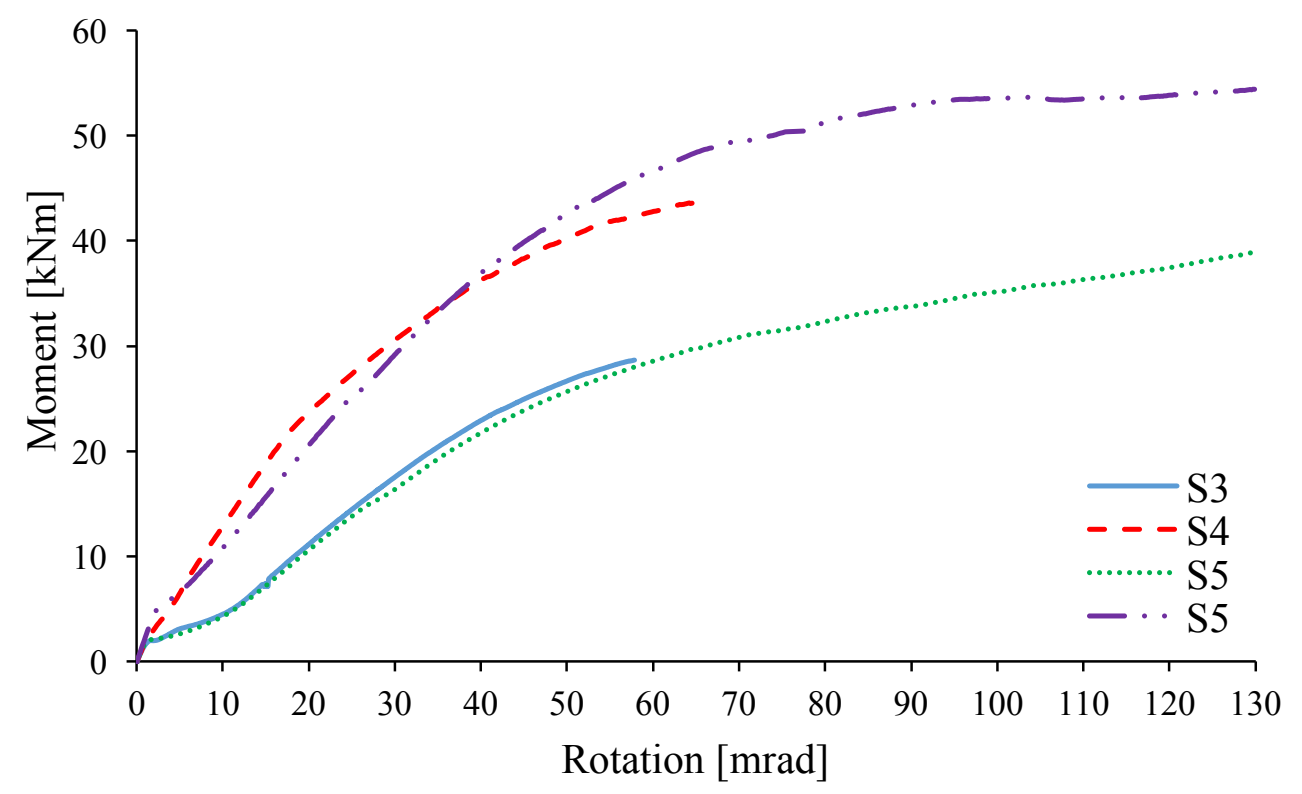

Figure 10. Moment-rotation relationship for Type 2 connections. 
1

2

3

4

5

6

7

8

9

10

11

12

13

14

15

16

17

18

19

20

21

22

23

24

25

26
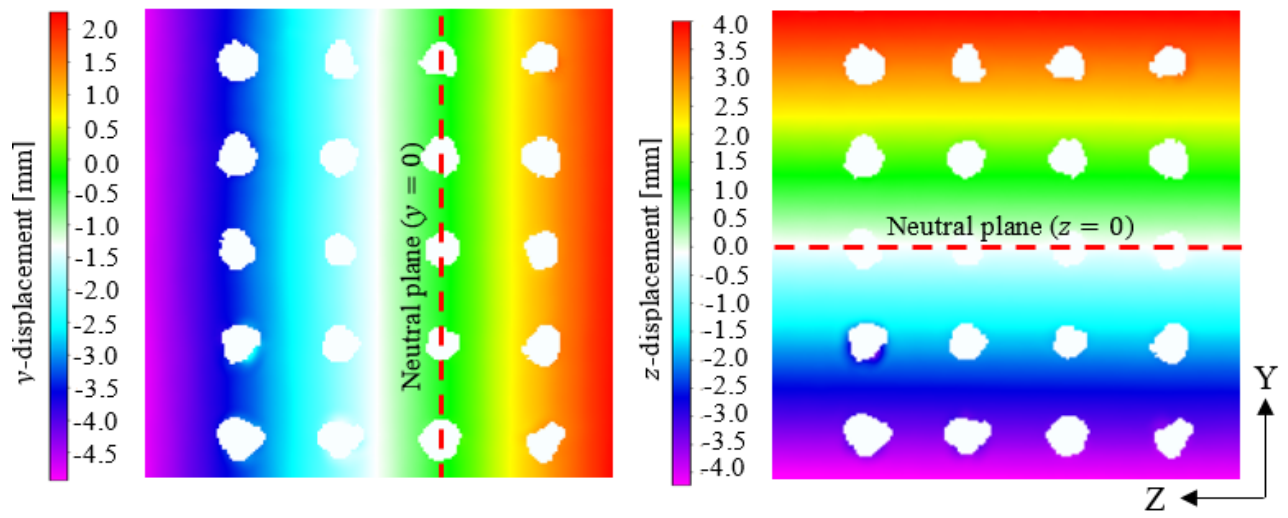

(a) $\mathrm{S} 5$
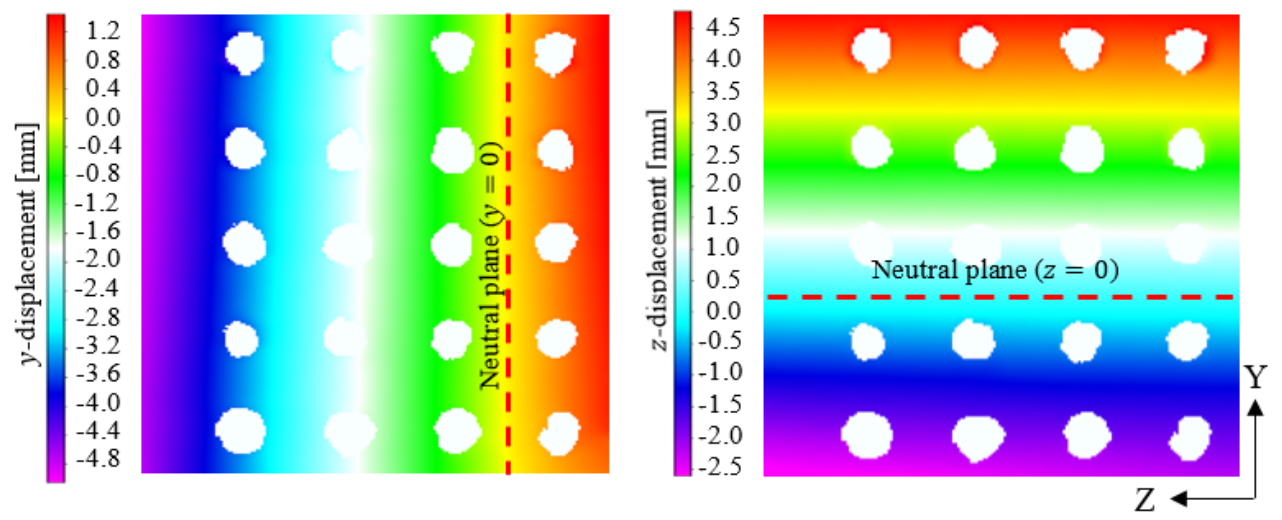

(b) $\mathrm{S} 6$

Figure 11. Displacement contours of specimens S5 and S6, at $34.02 \mathrm{mrad}$ of rotation.

Bolt-1
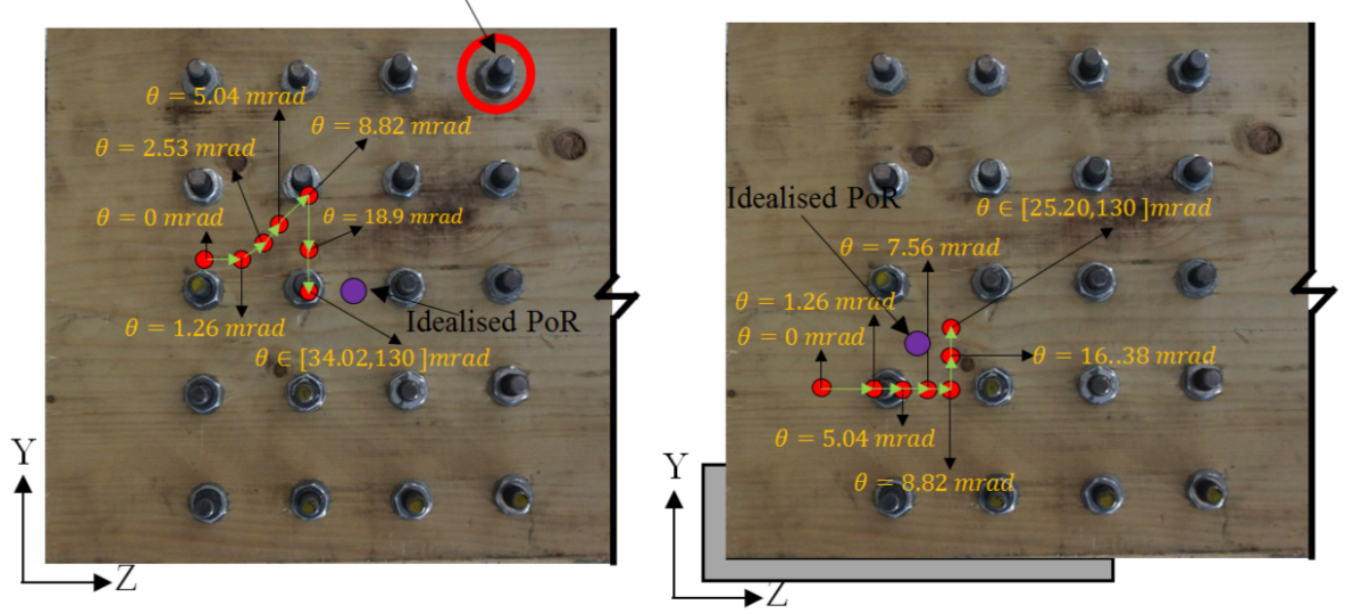

(a) S5

(b) S6

Figure 12. Evolution of the location of the point of rotation for specimens S5 and S6 at various rotations. 


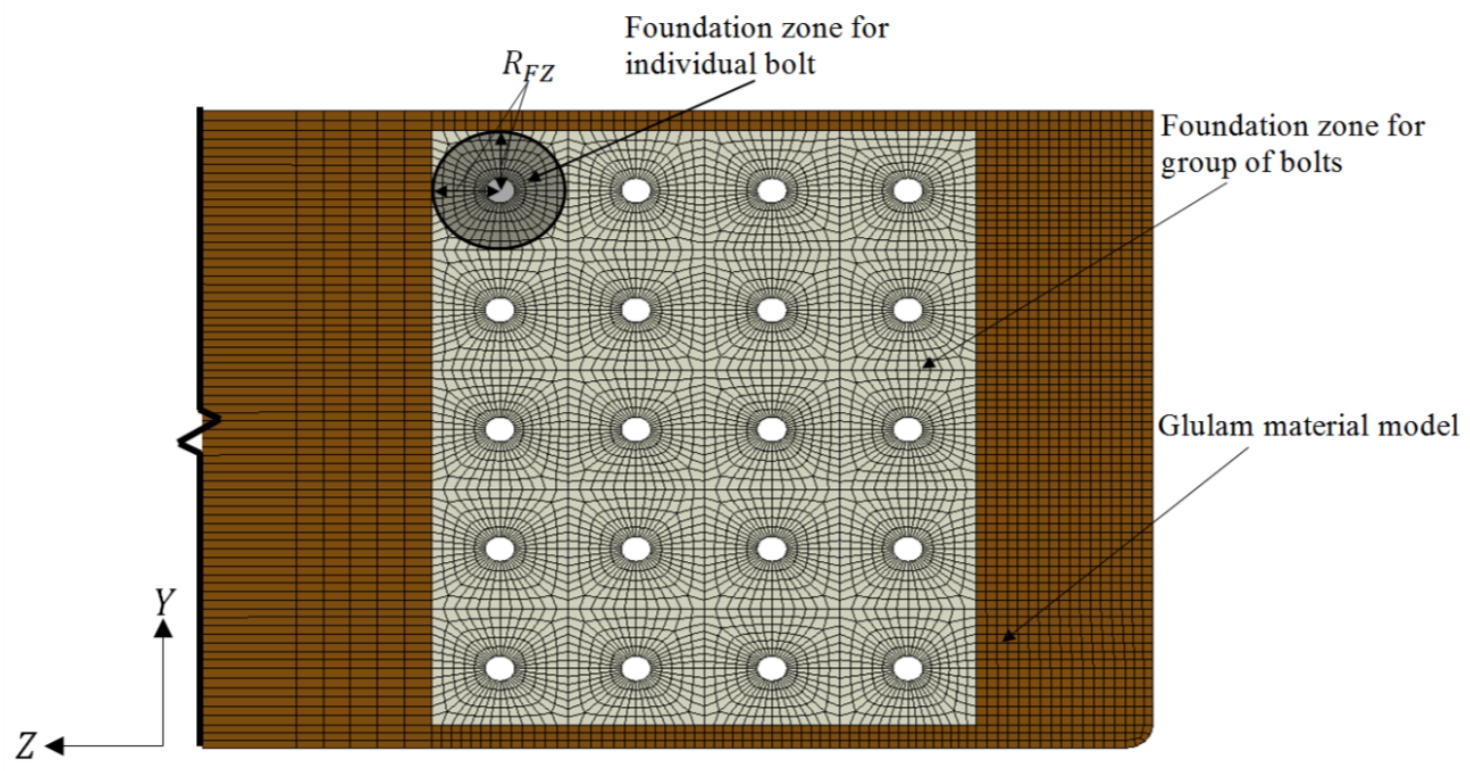

Figure 13. Implementation of the modified foundation FE model for the bolt group of Specimen S3 $(\mathrm{RFZ}=25 \mathrm{~mm})$.

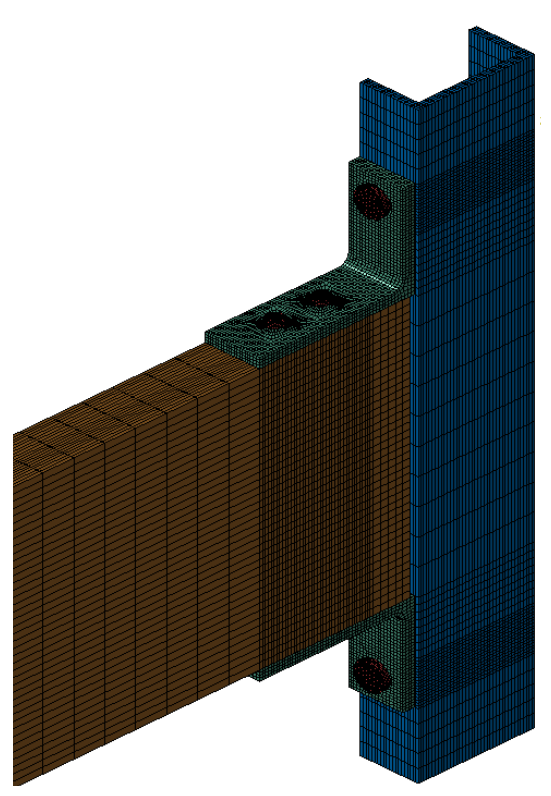

(a) Type 1 Connection

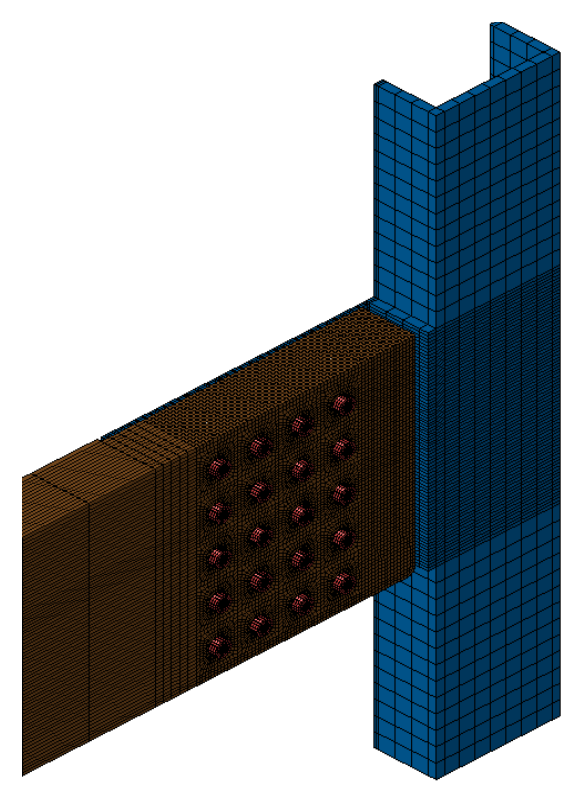

(b) Type 2 Connection

Figure 14. Numerical models of connection Types 1 and 2. 


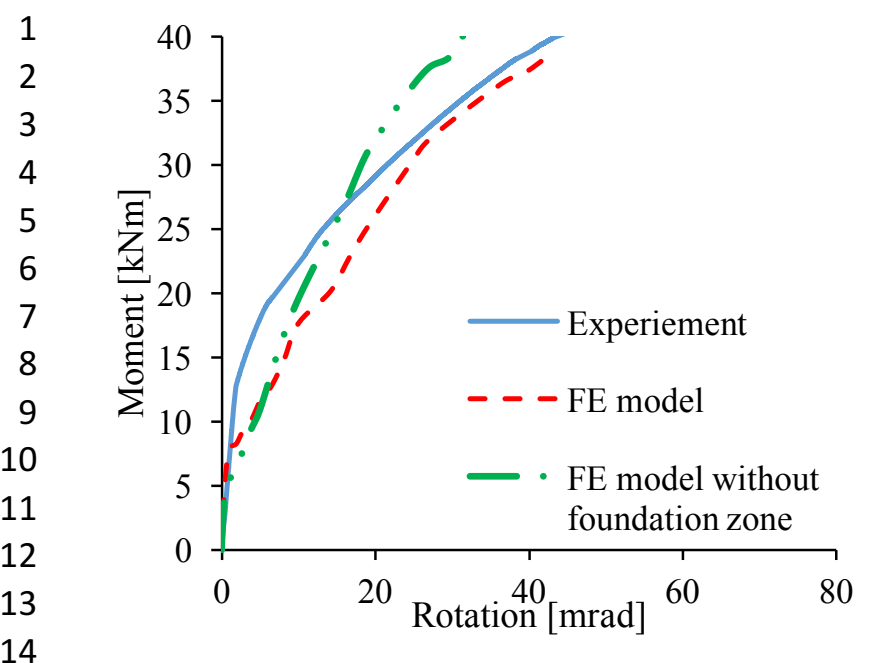

15

16

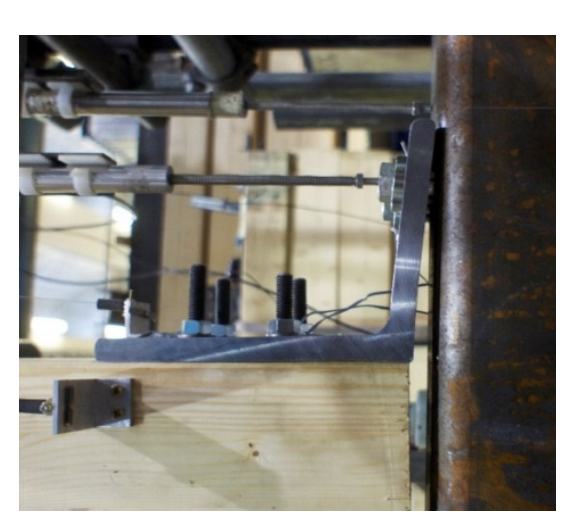

Experiment

(a) $\mathrm{S} 1$

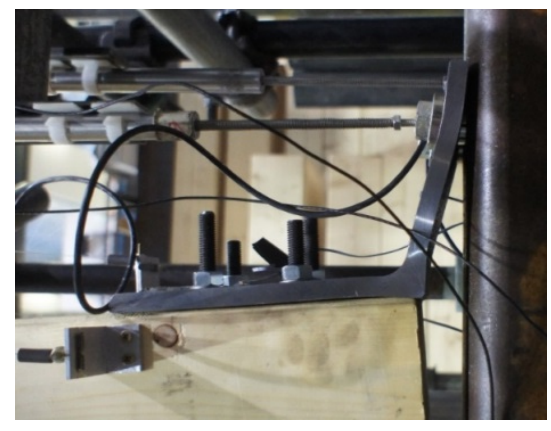

Experiment (b) S2

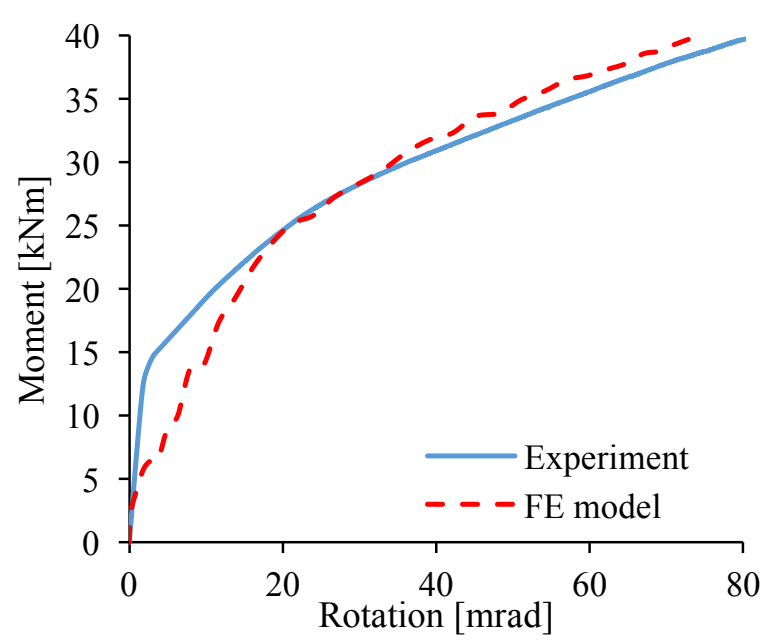

(b) S2

Figure 15. Comparison of moment-rotation response between experimental tests and FE model for connection configuration 1 .

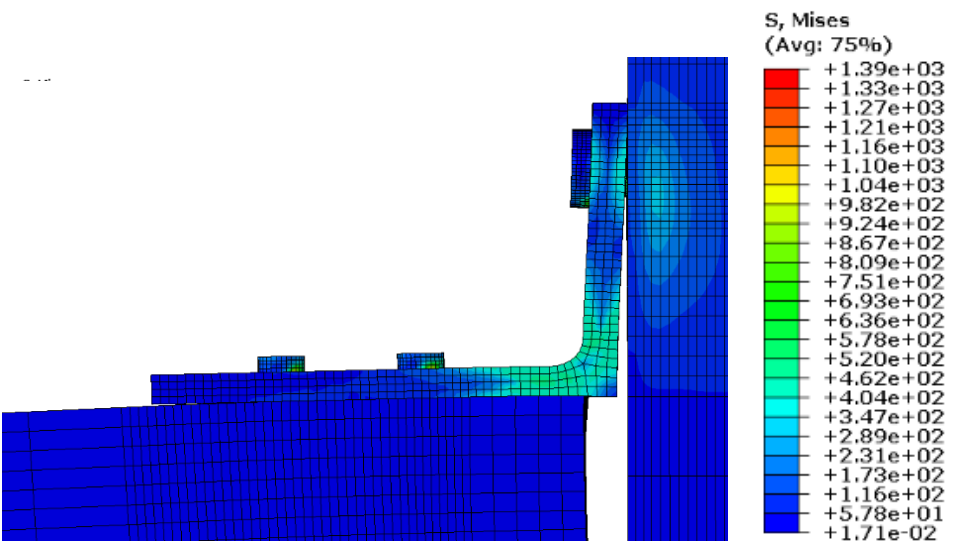

FE model

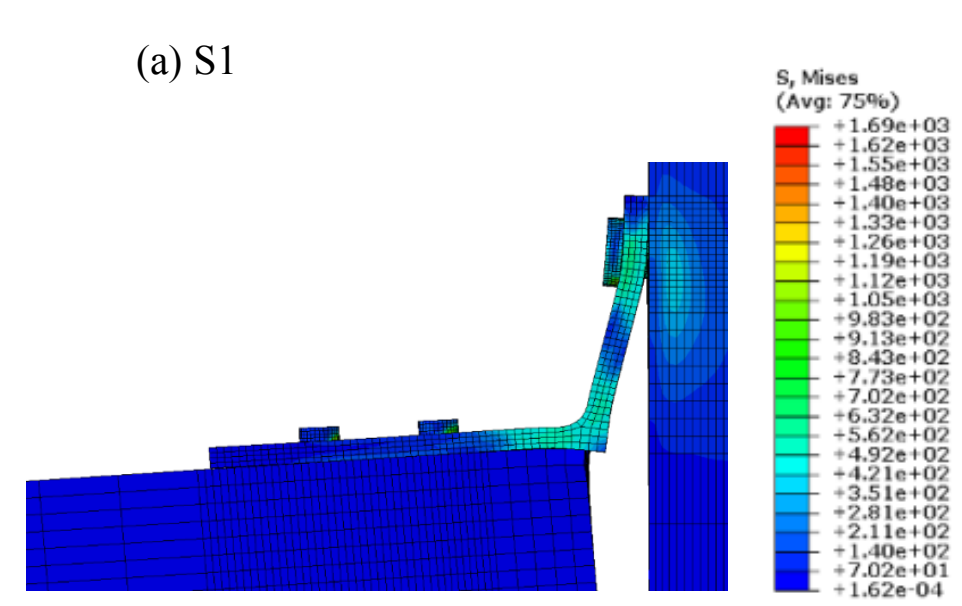

FE model

Figure 16. Comparison of top angle deformation patterns [Stress in MPa]. 
1

2

3

4

5

6

7

8

9

10

11

12

13

14

15

16

17

18

19

20

21

22

23

24

25

26

27

28

29

30

31

32

33

34

35

36

37

38

39

40

41

42

43

44

45

46

47

48

49

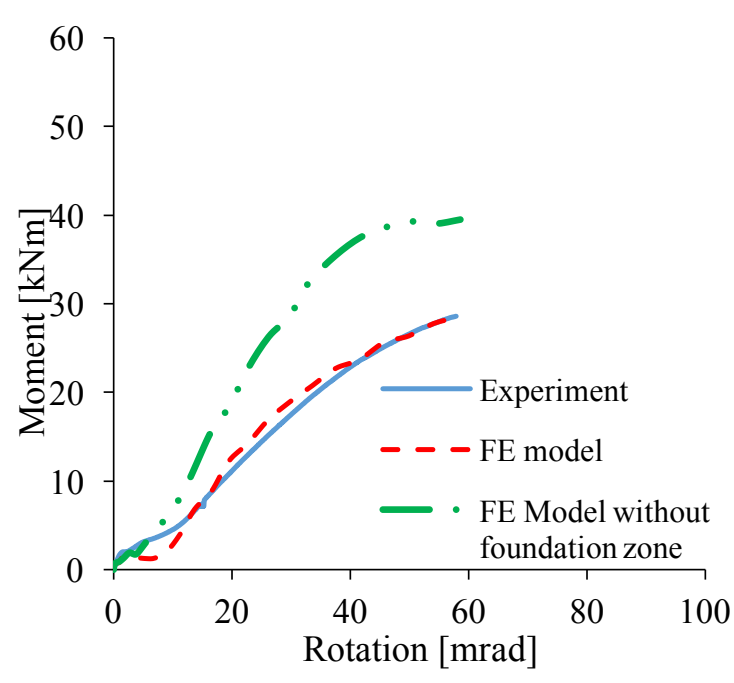

(a) S3

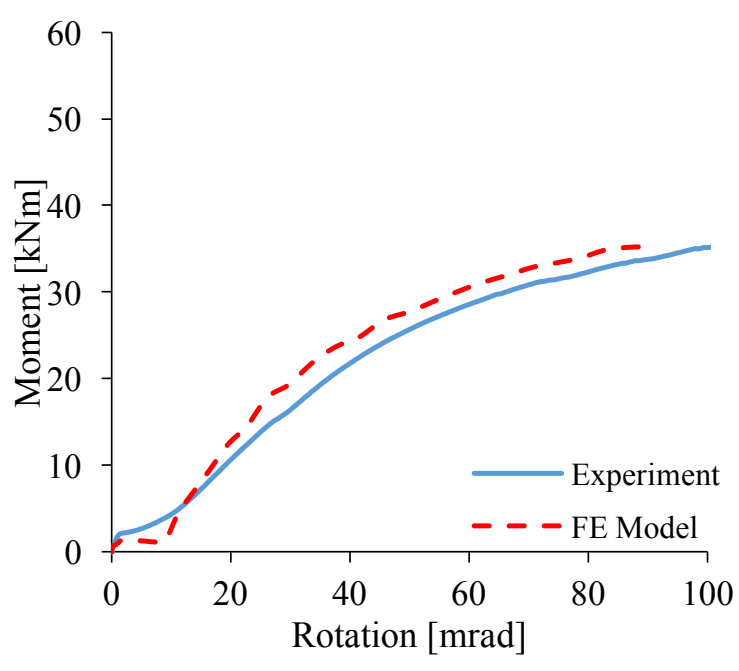

(c) S5

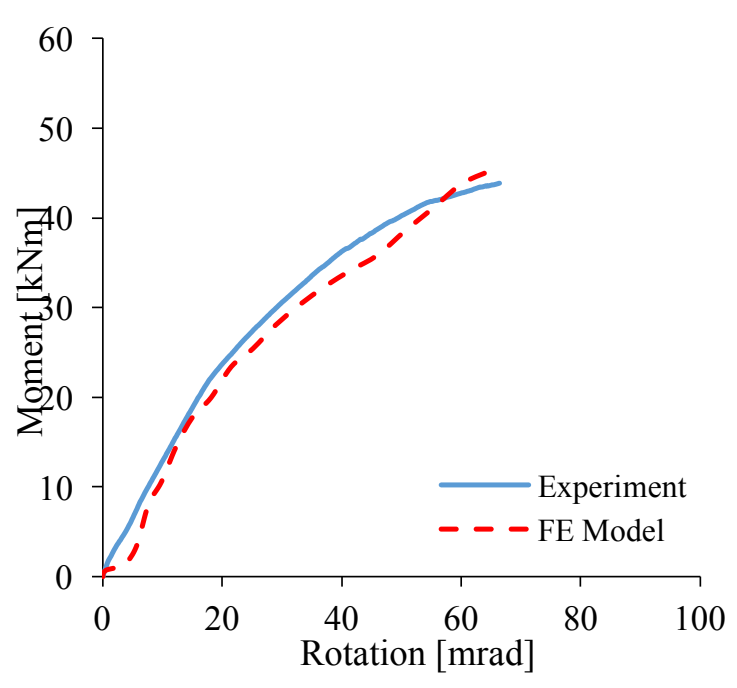

(b) $\mathrm{S} 4$

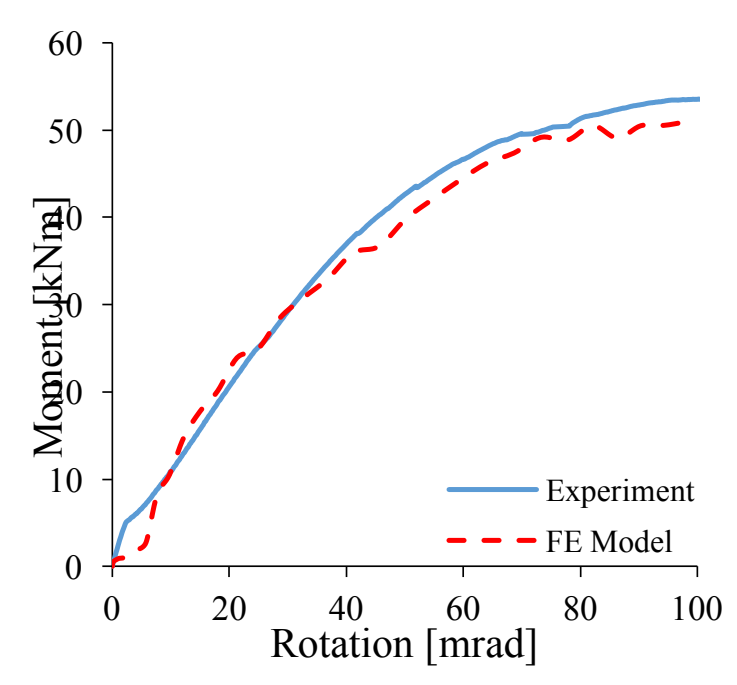

(d) S6

Figure 17. Comparison of moment-rotation response between experimental tests and FE model for Type 2 connections. 

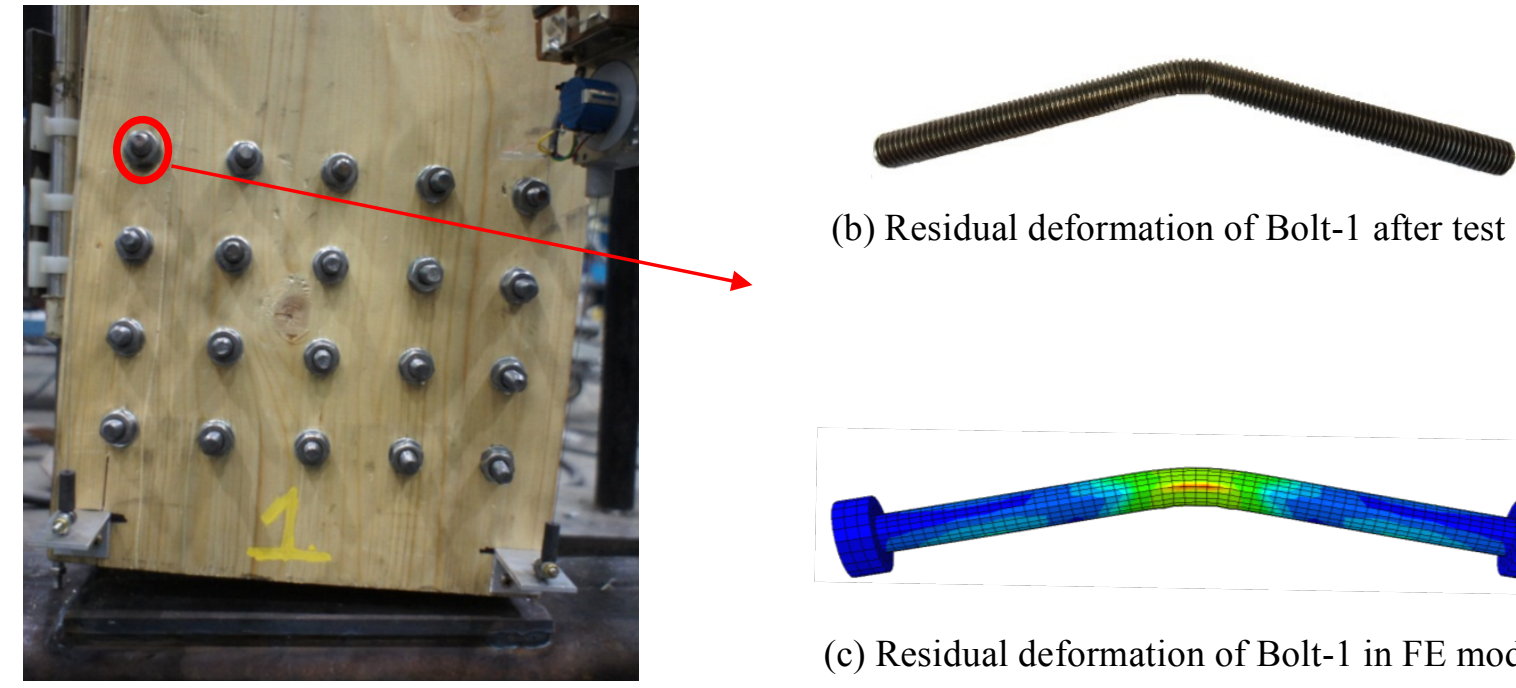

(b) Residual deformation of Bolt-1 after test

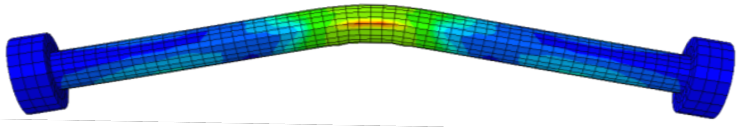

(c) Residual deformation of Bolt-1 in FE model

(a) $\mathrm{S} 3$

Figure 18. Comparison of bolt deformation pattern between experimental and FE model for Specimen S3.

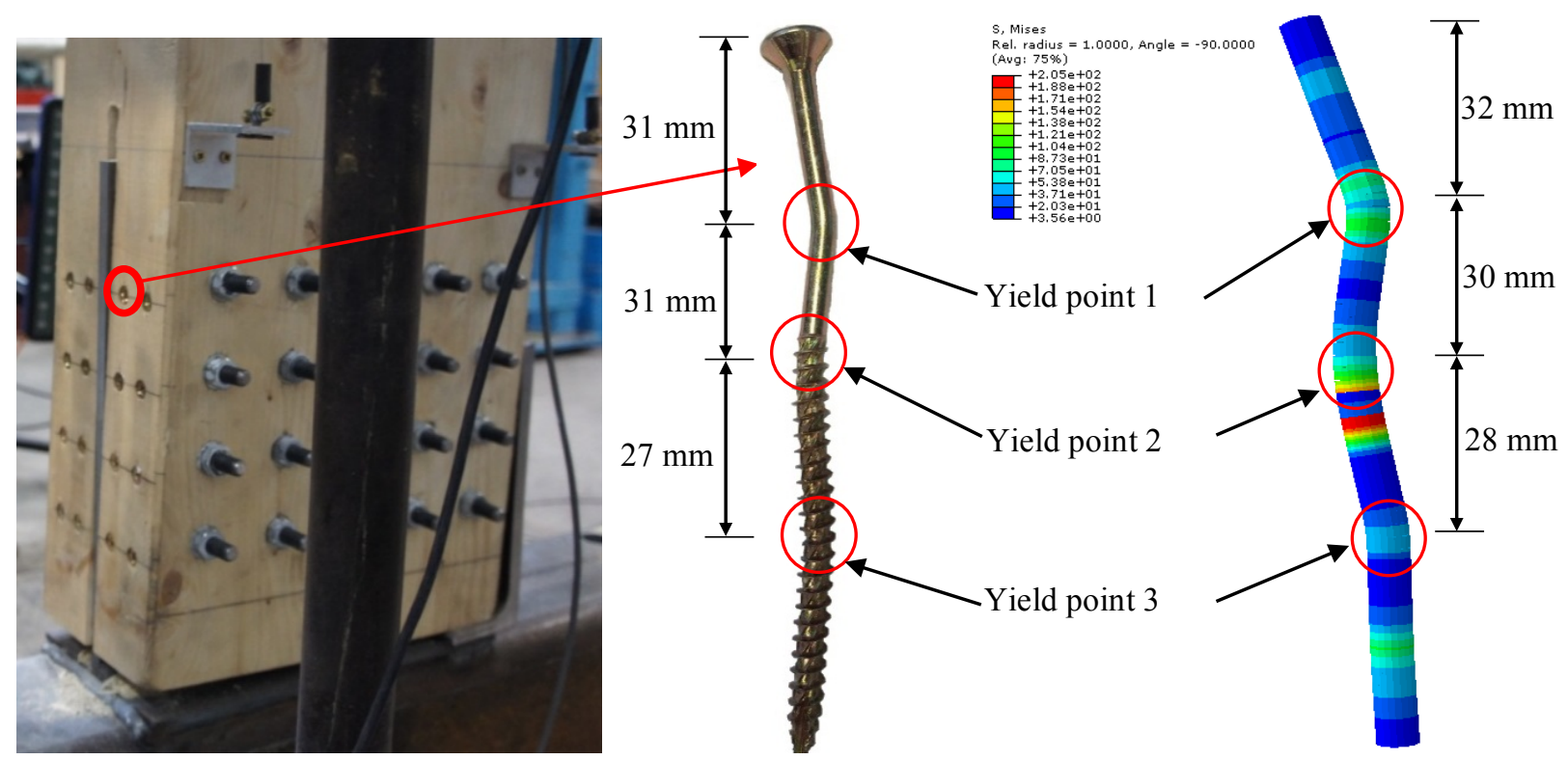

(a) C2T4AS

(b) Residual deformation of screw (c) Residual deformation of screw in FE model

Figure 19. Comparison of screw deformation pattern between experimental and FE model for Specimen S6. 


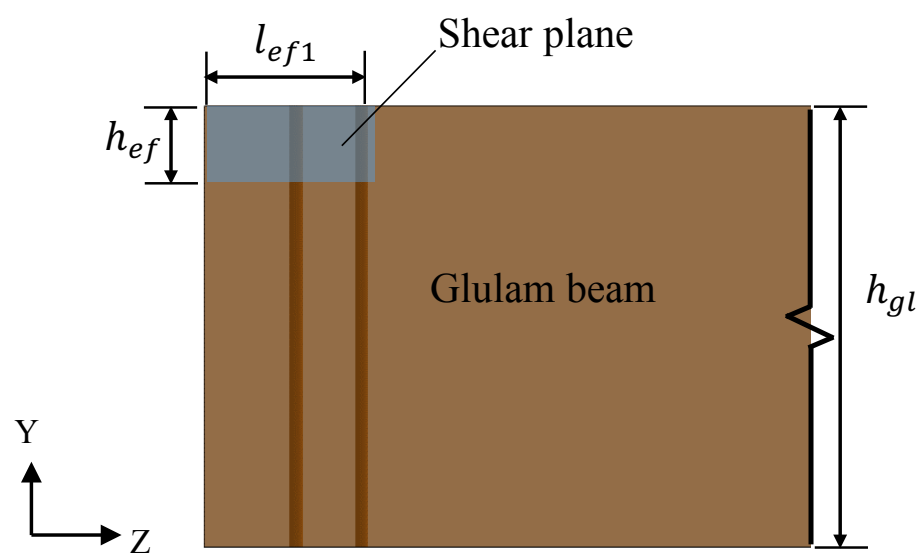

Figure 20. Shear plane generation for connection of configuration 1.

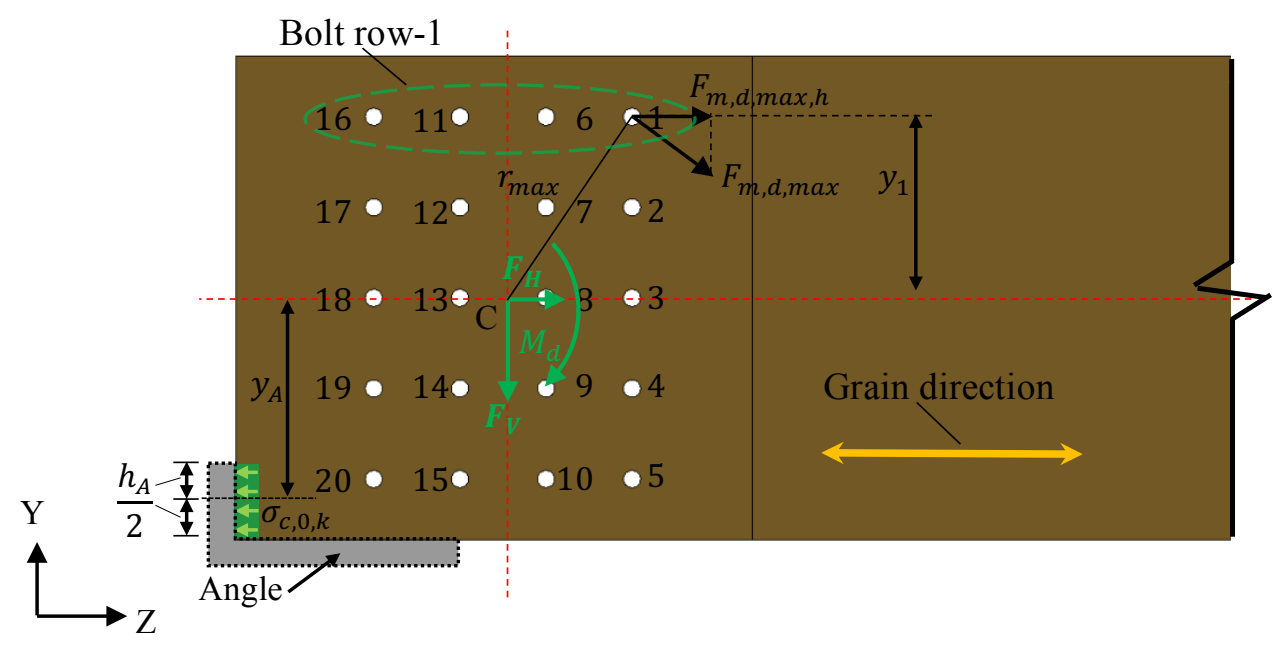

Figure 21. Schematic view of a Type 2 connection under generalized loading.

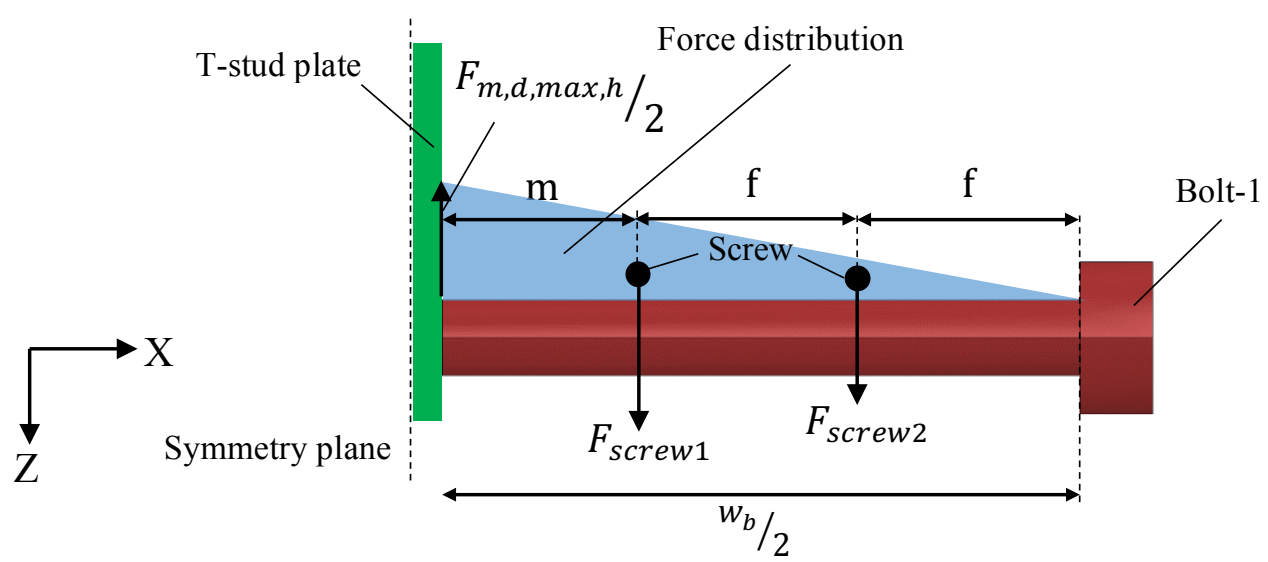

Figure 22 - Forces applied to Bolt-1 when screws are inserted to the beam. 


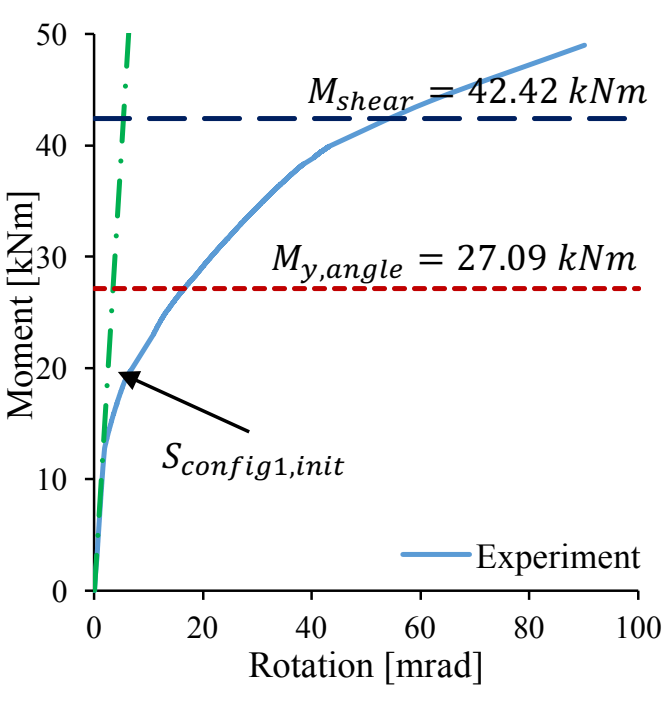

(a) $\mathrm{S} 1$

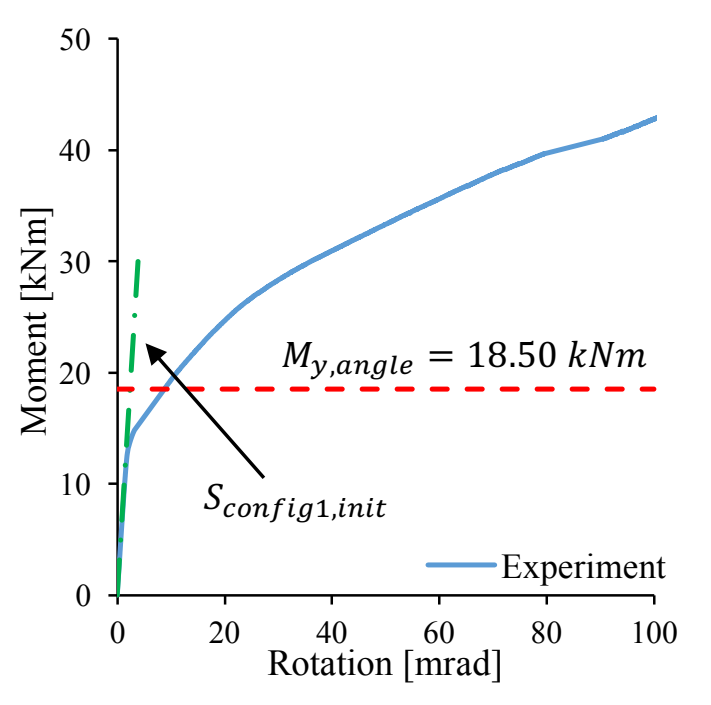

(b) $\mathrm{S} 2$

Figure 23. Comparison of moment-rotation response between experimental tests and component-based estimation for connection configuration 1. 
1

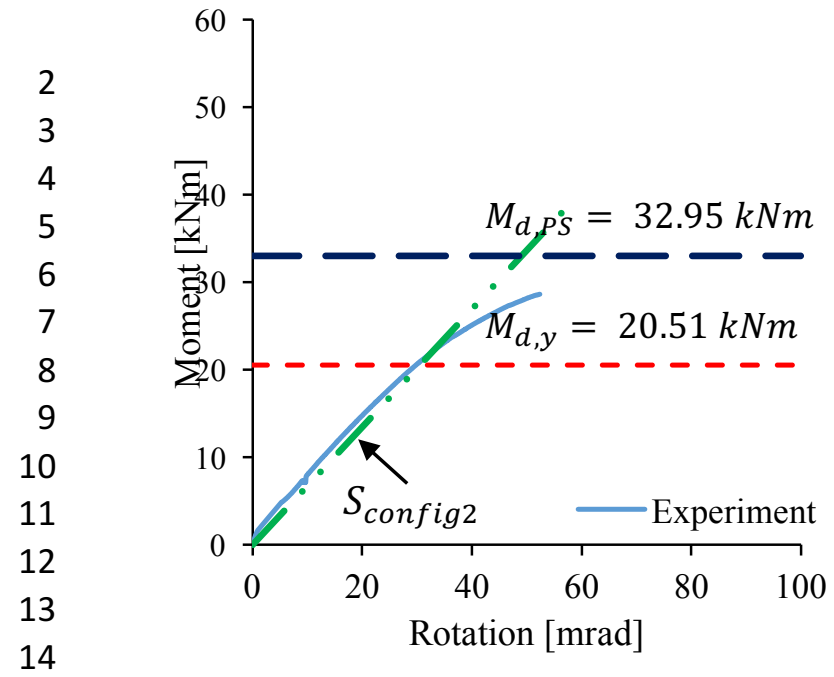

(a) S3

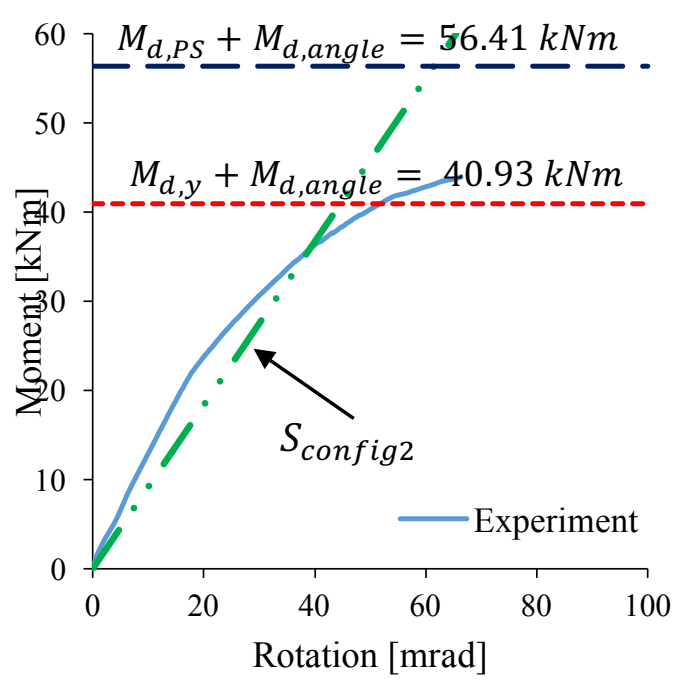

(b) $\mathrm{S} 4$

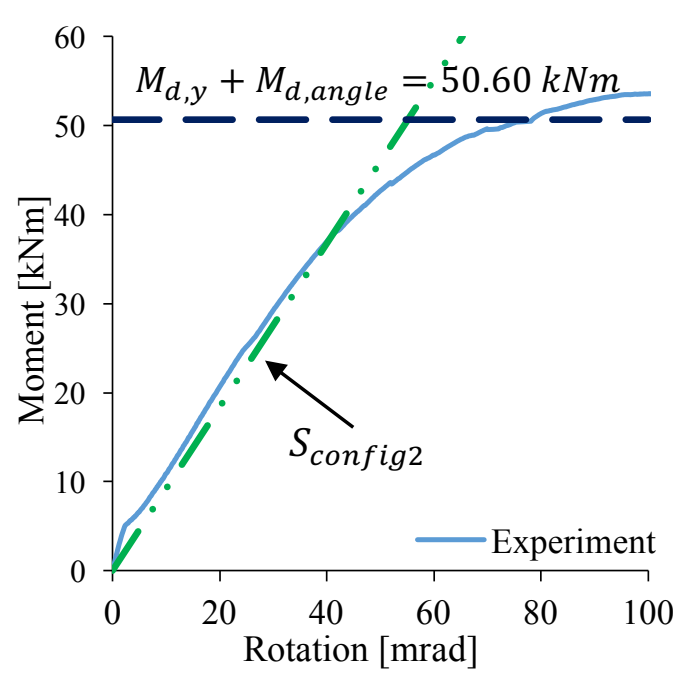

(d) S6

Figure 24. Comparison of moment-rotation response between experimental tests and mechanical model for connection configuration 2 . 


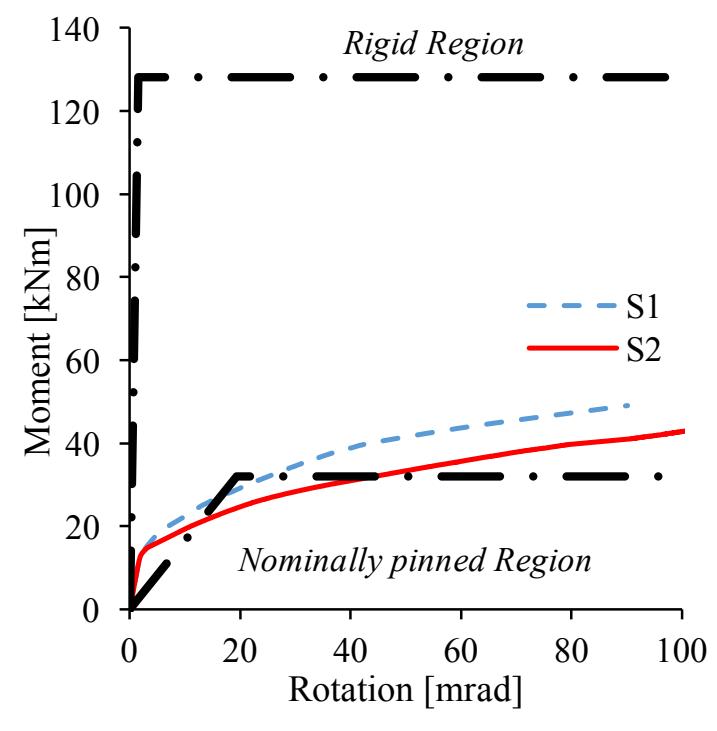

(a) Type 1 connections

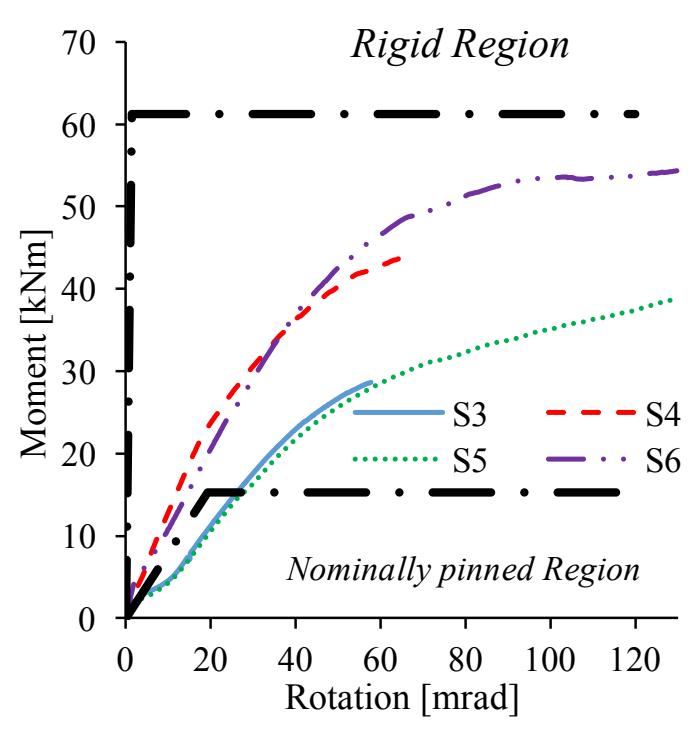

(b) Type 2 connections

Figure 25. Eurocode 3 [20] connection classification for the two connection types. 